\title{
Levels of description and explanation in meaning construction*
}

\author{
Ricardo Mairal Usón \\ Francisco José Ruiz de Mendoza Ibáñez
}

This chapter proposes the Lexical Constructional Model (LCM) as an explanatorily adequate model for the investigation of meaning construction at all levels of linguistic description, including pragmatics and discourse. The LCM has an argument structure module or level 1 module consisting of elements of syntactically relevant semantic interpretation. Then it has three basically idiomatic modules dealing with cognitively entrenched meaning implications deriving from the application of low-level and highlevel inferential schemas (levels 2 and 3 respectively) and with discourse aspects of meaning, especially cohesion and coherence phenomena (level 4). Each level is either subsumed into a higher-level constructional configuration or acts as a cue for the activation of a relevant conceptual structure that yields an implicit meaning derivation. Interaction between lexical and constructional configurations (at whatever description level) is regulated by a number of constraints that are either internal or external to the process.

\footnotetext{
${ }^{*}$ Financial support for this research has been provided by the DGI, Spanish Ministry of Education and Science, grants HUM2004-05947-C02-01/FILO, HUM2005-02870/FILO, and HUM200765755/FILO. The research has been co-financed through FEDER funds. We are grateful to two anonymous referees, to Professor Christopher S. Butler (Swansea), and to the members of the Lexicom research group (www.lexicom.es) for comments and advice on a preliminary version of this contribution. Any remaining error is our own responsibility.
} 


\section{Introduction}

Over the past few years the proponents of some linguistic approaches have relaxed the harsh tone that had presided over the linguistic debate for well over three decades and have gradually come closer to recognizing that a comprehensive theory of language demands the joint efforts and serious commitment of supposedly competing theories (cf. Jackendoff 2002: xv). A clear example of this gradual approximation of positions is the one that is taking place between the functional and the cognitively-oriented constructionist approaches to language (e.g. Culicover and Jackendoff 2005; Jackendoff 2002, 2007; Levin and Rappaport 2005; Nuyts 2005). This approximation is not surprising since the two paradigms share their emphasis on the communicative dimension of language. But the explanations offered on each side are too frequently based on opposing views on crucial theoretical issues, such as the role of verbal semantics, the nature of the syntax-semantics interface, and the role of constructions, to name just a few. ${ }^{1}$ This fundamental problem, coupled with the vast amount of work carried out within each perspective, supplying explanations at all levels of linguistic enquiry, makes the task ahead a gigantic one. But it is a necessary enterprise if we want to understand, in full detail and in an integrated manner, the many dimensions of language.

It is in this context of reconciliation between paradigms that the Lexical Constructional Model (hereafter LCM) has to be placed (Ruiz de Mendoza and Mairal 2007a, 2007b, 2008a, 2008b). ${ }^{2}$ The primary concern of the LCM is to develop a usage-based, comprehensive theory of meaning construction that aims to give explanations of how all aspects of meaning, including those that go beyond so-called core-grammar (e.g. traditional implicature, illocutionary force, and discourse coherence) interact with one another. For reasons that will become apparent later on, this concern leads to the rejection of unsubstantiated dichotomies that have become part of the most recent linguistic debate, especially verb-centered projectionism (e.g. Role and Reference Grammar; RRG; S. C. Dik's Functional Grammar; FG)

\footnotetext{
${ }^{1}$ For a detailed discussion of the typology of functional models and of their points of convergence and divergence with cognitive accounts of Construction Grammar, we refer the reader to Butler (2003), Butler and Gonzálvez-García (2005) and Gonzálvez-García and Butler (2006).

${ }^{2}$ For further information on the Lexical Constructional Model we refer the reader to the LEXICOM research webpage: $<\underline{w w w . l e x i c o m . e s}>$
} 
versus the constructional approach, as propounded by Kay and Fillmore (1999), Goldberg (1995, 2006), Croft (2001), and Bergen and Chang (2005), among others. The LCM argues that both perspectives are really necessary if we want to account for the vast range of phenomena involved in meaning construction.

Another relevant aspect of the LCM is its special focus on finding unifying features across the various levels of linguistic description and explanation. This is achieved by working under the assumption that, unless there are well-evidenced reasons to the contrary, all levels of linguistic description and explanation make use of the same or at least comparable cognitive processes (cf. Ruiz de Mendoza 2007). This assumption, which we call the equipollence hypothesis, is a methodological one and has allowed us to introduce a large degree of regularity and parsimony in our exploration. Thus, we postulate that metaphor and metonymy go beyond the lexical level of explanation and have a place in constraining lexical-constructional interaction and also in supplying inference schemas at the pragmatic level. Other cognitive processes, such as generalization and parametrization also have a role as constraining factors at all levels of meaning construction. We further argue that inferential activity, which we call cued inferencing or cueing, is not only a matter of the pragmatic and discourse levels, but also has a place on the predicate-argument level of grammatical description, which constitutes the central or "core" level of the LCM. Finally, we see idiomaticity as an active process not only with reference to the lexicon but also constructionally and at all levels of description.

In order to give an account of the way the LCM differs from other cognitive and functional models in dealing with the interrelation between the various levels of linguistic description and explanation in meaning construction, we have designed the present chapter as follows. First, we place our model within the context of the projectionist versus constructionist dichotomy. Second, we discuss the problem of lexical representation by contrasting the decompositional and frame-based perspectives and argue for the notion of lexical template as an alternative form of lexical representation that integrates relevant elements from the other two perspectives. Third, we discuss syntactically-relevant non-lexical representations. These are divided into idiomatic and non-idiomatic (or argument) constructions. The latter have been the main object of research in Construction Grammar accounts, so we focus our attention on the former and on the role these constructions play in meaning derivation. We distinguish implicative, illocutionary, and discourse 
constructions and study their main features from a descriptive perspective. Finally, in order to give our account full explanatory adequacy, we explore the way in which the meaning creation process is constrained by cognitive principles. We distinguish between two forms of working out meaning, cued inferencing and subsumption, and address the way each step of the meaning generation process is internally and externally constrained on the basis of cognitive mechanisms. In general, our discussion addresses the various aspects of the overall architecture of the LCM, as diagrammed in Figure 1, which is borrowed from Ruiz de Mendoza and Mairal (2008a).

[Figure 1 near here]

\section{Projections vs. constructions}

The proliferation of frameworks (both formal and functional) that have been propounded in linguistics over the last years, or even the different offshoots that compete within the same linguistic school, such as the various versions of Construction Grammar or the many different functional theories ${ }^{3}$ are an eloquent proof that linguistic inquiry has been intense and active, thus offering a wide range of different methodological options for the researcher. As things stand, it might sound somewhat bizarre to offer a new linguistic product in a really saturated linguistic market. What are the added advantages that a new model can offer over the already existing proposals?

In connection with this, the LCM emerges as an attempt to reconcile a spurious debate between the projectionist and constructivist accounts of language and reorient this cardinal theoretical issue within the larger context of a theory of language that aspires to provide a fully-fledged and fine-grained description of all aspects of meaning construction. If this is our goal, we certainly need to capture the most relevant elements of the projectionist and the constructionist accounts. But before we discuss what these elements are, let us briefly discuss some of the competing theoretical issues that have fragmented functional and constructionist approaches.

\footnotetext{
3 According to Nichols (1984), these range from 'extreme' and 'moderate' to 'conservative' (see also Butler, 2003). A much more detailed and updated description of functional approaches in comparison with cognitive theories can be found in Gonzálvez-García and Butler (2006).
} 
This will serve as a backdrop against which we will briefly outline the architecture of the LCM.

One of the central assumptions of many functional accounts of grammar is that the syntactic configuration of predicates can largely be determined on the basis of their argument structure, which is described in terms of logical configurations. For this reason, these functional accounts can be labeled "projectionist", i.e. they claim that the logical structure of predicates constrains syntax by being mapped onto it. However, as has been extensively shown in Construction Grammar circles, there are instances where the argument structure of a predicate proves insufficient to explain the occurrence of one constituent. Consider the examples in (1) which exemplify the fact that constructions may contribute arguments to yield the final semantic interpretation of a particular expression: ${ }^{4}$

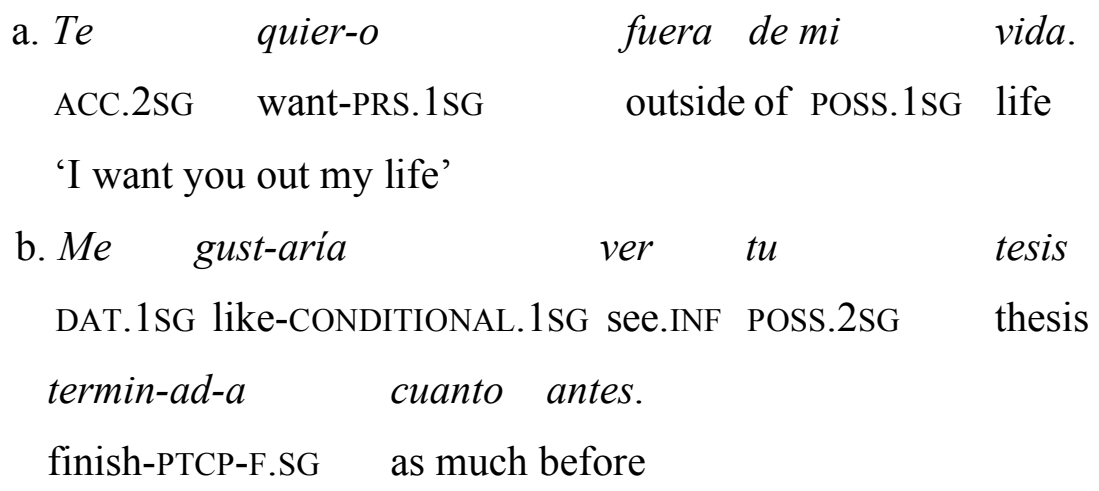

'I would like to see your thesis completed as soon as possible'
c. Ver-emos su
tesis termin-ad-a
pronto.
see-FUT.1PL POSS.2SG thesis finish-PTCP-F.SG soon
'We will see your thesis completed soon'
d. Te ve-o en la Moncloa
ACC.2SG see-PRS.1SG in DEF.F.SG Moncloa[NAME]
en cinco año-s.
in five year-PL

\footnotetext{
4 Interlinear morpheme-by-morpheme glosses are supplied for the Spanish examples following the Leipzig Glossing Rules (see http:/www.eva.mpg.de/lingua/resources/glossing-rules.ph). The following additional abbreviations will be used in this paper: conditional (conditional or potential verb tense), and reflex passive (reflex passive).
} 
In (1a) the PP fuera de mi vida cannot be derived from the argument structure of the predicate 'quiero'. In our view, (1a) exemplifies in Spanish the caused-motion construction, which has been studied for English (e.g. He sneezed the napkin off the table) in quite a lot of detail by Goldberg (1995, 2006). The caused-motion construction is used with causative and volition predicates and expresses a categorical and strong manipulation of the state of affairs denoted in the NP and the XPCOMP. In (1b) the resultative predicate terminada (completed) is not part of the argument structure of the predicate ver (see). In much the same way, in (1c) the complex resultative expression en la Moncloa en cinco años, where 'Moncloa' is metonymic for 'the Spanish government', originates in a non-explicit action with an observable or imaginable endpoint (i.e., someone's political career).

In essence, the examples in (1) show that constructions should not be regarded as pure epiphenomena since they play an active role in determining the type of syntactic configuration in which a predicate occurs. As a matter of fact, the LCM agrees with this aspect of Godlberg's Construction Grammar, thereby incorporating into its core-grammar level of description an inventory of argument constructions. But the LCM differs from Goldberg's account in significant respects, especially the descriptive metalanguage, which resembles that used for lexical characterizations of verbal predicates, and the specification of the ways in which core-grammar argument constructions interact with lexical configurations and with other constructions, whether constructional or idiomatic, at other levels of description.

\section{The role of verbal semantics}

Lexical representation has become a crucial issue in linguistic theory, especially after the discovery that many of the syntactic properties of a predicate are in large part determined by its argument structure, a methodological stance that has become a hallmark for projectionist theories. This obviously contrasts with the ancillary status to which verbal semantic has been relegated in constructionist circles, where verbal 
semantics is not an area of emphasis. ${ }^{5}$ Consider the following projectionist representational format for three semantically close verbal predicates, viz. assassinate, murder, and kill (Dik 1997a: 101):

$$
\begin{gathered}
\text { assassinate }[\mathrm{V}]\left(\mathrm{x}_{1}:<\text { human }>\right)_{\mathrm{Ag}}\left(\mathrm{x}_{2}:<\text { human }>\right)_{\mathrm{Go}} \leftrightarrow \\
\text { murder } \left.[\mathrm{V}]\left(\mathrm{x}_{1}\right)_{\mathrm{Ag}}\left(\mathrm{x}_{2}\right)_{\mathrm{Go}}\left(\mathrm{x}_{3}: \text { treacherous }[\mathrm{A}]\right)\right)_{\mathrm{Manner}} \\
\text { murder }[\mathrm{V}]\left(\mathrm{x}_{1}:<\text { human }>\right)_{\mathrm{Ag}}\left(\mathrm{x}_{2}:<\text { human }>\right)_{\mathrm{Go}} \leftrightarrow \\
\text { kill } \left.[\mathrm{V}]\left(\mathrm{x}_{1}\right)_{\mathrm{Ag}}\left(\mathrm{x}_{2}\right)_{\mathrm{Go}}\left(\mathrm{x}_{3}: \text { intentional }[\mathrm{A}]\right)\right)_{\text {Manner }} \\
\text { kill }[\mathrm{V}]\left(\mathrm{x}_{1}\right)_{\mathrm{Ag} / \mathrm{Fo}}\left(\mathrm{x}_{2}:<\text { human }>\right)_{\mathrm{Go}} \leftrightarrow \\
\text { cause } \left.[\mathrm{V}]\left(\mathrm{x}_{1}\right)_{\mathrm{Ag} / \mathrm{Fo}}\left(\mathrm{e}_{1}:\left[\text { die }[\mathrm{V}]\left(\mathrm{x}_{2}\right)\right)_{\text {Proc }}\right]\right)_{\mathrm{Go}}
\end{gathered}
$$

Each characterization is a predicate frame. For each argument of the predicate frame, the characterization specifies its selection restrictions (between angled brackets) and its semantic role (or function). Other distinguishing features are part of the definition part of the formalism. The explicit connection between the argument structure of the predicate and two syntactically relevant dimensions of semantic interpretation (selection restrictions and semantic functions) endows the representational format with a clear semantically-motivated syntactic projection potential. The rest of the features allows us to assign each item its due place in a lexical class.

Consider now the different projectionist system of lexical representation provided by Van Valin and LaPolla (1997):

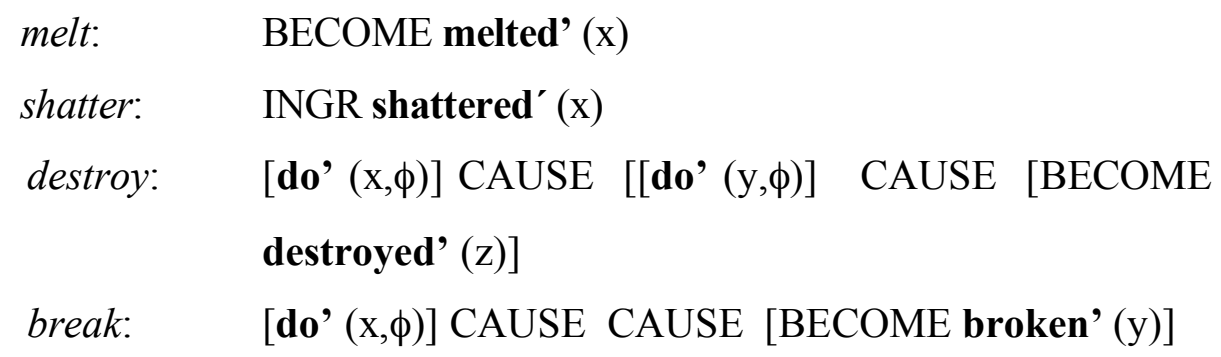

\footnotetext{
${ }^{5}$ While not opposed to the study of verbal semantics, most constructionist approaches agree that constructions are better predictors of sentence meaning than verbal semantics (cf. Goldberg, Casenhiser and Sethuraman, 2005). Croft (2001) and Boas (2003) are exceptions. These two scholars vindicate the relevance of verbal semantics in the context of constructional accounts. The LCM takes sides with this position but also seeks to maximize it by endowing the LCM with a robust lexical component, as described in sections 4 and 5 below.
} 
These formalisms do not include selection restrictions or semantic functions. Instead, they make use of an abstract semantic metalanguage which consists of a number of primes (or constants) together with a list of operators and variables. Another variant of this line of research is represented by Levin and Rappaport's (2005) event structure templates. As argued in Ruiz de Mendoza and Mairal (2008b), one of the problems of this approach is that these representations only capture those aspects of the meaning of a word that have syntactic projection, at the cost of ignoring relevant knowledge parameters that are also part of a speaker's lexical competence. One further problem is the inability of these representations to account for many every-day uses of concepts that would require a broader definitional approach. Thus, there is no way in which representations like these can allow us to predict why break may be used intransitively (e.g. The window broke) but destroy may not (e.g. *The building destroyed). The predicates broken' and destroyed' have to be decomposed further, an issue that we shall deal with in section 7.2 below.

Alternatively, cognitive linguists make use of encyclopedic information in the form of frames as developed in Frame Semantics and more recently in the FrameNet project. ${ }^{6}$ Semantic frames, which have been described as "specific unified frameworks of knowledge, or coherent schematizations of experience" (Fillmore 1985: 223), are schematic representations of situation types (e.g. 'buying', 'drinking', 'reading', etc.) describable in terms of participants and their roles (cf. Fillmore and Atkins 1992, 1994). Frames are very different from event structure templates or logical structures. Thus, frames do not include formal representations of the parameters that are determinant for argument realization. Instead, frames provide a comprehensive account of the conceptual framework underlying the meaning of a predicate, which can account for many aspects of its use. Thus, the commercial frame specifies a buyer, a seller, some merchandise, money, and a marketplace, among other elements. The ingestion frame specifies an ingestor, a thing that is ingested (an “ingestible"), an instrument, a place, a time, the manner of ingesting, and so on. The reading frame has, among others, slots for a reader, something that is read (e.g. a book), a place (e.g. a library, a study room). The advantage for grammatical explanation of this kind of account is that it deals with the different ways in which

\footnotetext{
${ }^{6}$ For an updated account of the FrameNet Project, see http://framenet.icsi.berkeley.edu
} 
verbal predicates profile relations and how this affects grammatical realization. For example, pay relates to the part of the transaction frame that deals with the transfer of money from buyer to seller in order for the latter to receive goods. Not all these elements of semantic structure need to be realized in syntax:

(2) a. He didn't want to pay the car dealer (the agreed price) (for the car).

b. He didn't want to pay the agreed price (to the car dealer) (for the car).

It is possible to contrast the use of pay with other related verbal predicates instantiating the same frame in terms of how each profiles the same set of relations:

(2') a. He didn't want to buy the car (from the car dealer) (for the agreed price).

b. *He didn't want to buy the car dealer.

c. *He didn't want to buy the agreed price.

While pay may take two different frame elements as its grammatical object, this is not the case for buy. The motivation for this difference can be attributed to the fact that the verb buy profiles a relation between the buyer and the goods bought (i.e., the focus is on the buyer obtaining the goods), but pay profiles a relation between the buyer and the seller in terms of the price paid for the merchandise (i.e., the focus is on the buyer and the seller being involved in an exchange of money for goods).

One insufficiency of this approach, however, lies in its lack of representational systematicity, since labels for semantic structure elements are stipulated in a rather $a d$ hoc fashion without any standardized procedure. Thus, for the ingestion frame, we wonder why there is no specification of the way the actor and the affected entity interact: there is a causal connection that results in consumption of the affected entity, which will vary with the form of ingesting (eating, gulping, chewing, munching, drinking, sipping, devouring, consuming, gobbling, slurping, etc.). For example, one can eat a sandwich by taking small bites at it or by taking one or two big bites, but not by licking it. However, one can eat egg yolk this last way. The Frame Semantics system would need to postulate a virtually limitless number of subframes (eating a sandwich, a cake, ice cream, egg yolk, lamb, fish, rice, corn on the cob, etc.) for each 
way of ingesting food and make explicit the possible and impossible combinations between ways of ingesting and food types.

Another problem for the Frame Semantics approach is the lack of clear mechanisms to predict different forms of syntactic realization for each element of semantic structure. In order to do so, it is necessary to do much more than simply spell out connections between frames and the verbal predicates realizing them. For example, for a verb like charge we can postulate its potential to realize that part of the commercial transaction frame where someone (a customer) pays an amount of money for some work (e.g. The mechanic charged me $60 \$$ for just half an hour's work). However, the person that receives the money is not a seller of goods but a service provider. Are we to understand the concept of 'seller' in the commercial transaction frame in a broad manner? If so, how do we make explicit the restrictions that charge places on the type of seller on the basis of Frame Semantics? We could postulate a 'charging' subframe, but then we would need to postulate subframes for just about any verbal predicate connected with trading goods or services (e.g. bargain, haggle, deal, traffic, auction, transact, swap, market, retail, vend, supply, etc.) and then formulate the various syntactic realization restrictions. Evidently, this step would draw Frame Semantics very close to a projectionist account of lexical semantics. This is a theoretical development that frame semanticists have never wanted to make, ${ }^{7}$ but in our view it is a necessary one unless we want encyclopedic semantics to remain largely dissociated from syntactic theory, which is the actual situation in Cognitive Linguistics, where the different versions of Construction Grammar and even Langacker's Cognitive Grammar do not really incorporate it explicitly. ${ }^{8}$ There is thus an important mismatch within Cognitive Linguistics between its theoretical emphasis on the encyclopedic conception of meaning and its actual incorporation into an account of grammar.

\footnotetext{
7 Advocates of Frame Semantics have explicitly written against the projectionist account of verb classes proposed by Levin (1993) (cf. Baker and Ruppenhofer 2003; Boas 2006).

8 The focus of Langacker's Cognitive Grammar is on cognitive phenomena such as construal, perspective, subjectivity and mental scanning (cf. Langacker 1987, 1991, 1999, 2005, 2008), and Construction Grammar mainly deals with the distinct grammatical properties of constructional patterns based on thematic roles. The need to incorporate a proper syntactic component has also been explicitly put forward in Boas (2008).
} 
The LCM is an attempt to solve this problem. In order to combine the two systems, i.e. constructionalism and projectionism, the LCM has developed a system of lexical representation in terms of lexical templates, which combine (encyclopedic) semantic and logical variables that are linked to one another in readiness for syntactic projection.

\section{Lexical templates}

The notion of lexical template is originally a development of the logical structures in Role and Reference Grammar (RRG) (cf. Van Valin and LaPolla 1997; Van Valin 2005, 2008). RRG uses a decompositional system for representing the semantic and argument structure of verbs and other predicates (their Logical Structure, LS). The verb class ascription system is based on the Aktionsart distinctions proposed in Vendler (1967), and the decompositional system is a variant of the one proposed in Dowty (1979). Verb classes are divided into states, activities, achievements, semelfactives, and accomplishments, together with their corresponding causatives. In Table 1 we give a representation of each verb class with its corresponding formalism (cf. Van Valin 2005:45).

[Table 1 near here]

RRG maintains that state and activities are primitives and thus form part of the logical representation of the rest of predicates; by way of example, an accomplishment is either a state or activity predicate modified by the telic operator BECOME. However, Van Valin and Wilkins (1993) and Van Valin and LaPolla (1997) all claim quite explicitly that state and activity atomic predicates need further semantic decomposition and thus provide a first approach for the predicate remember and speech act verbs respectively. ${ }^{9}$

In an attempt to provide logical structure with a more robust semantic decomposition, we decided to develop the notion of lexical template. A lexical template consists of two modules: (i) the semantic module, and (ii) the logical

\footnotetext{
${ }^{9}$ For a discussion of the exact details of the formalism of the first lexical templates, we refer the reader to Van Valin and Wilkins (1993), Van Valin and LaPolla (1997), Mairal and Faber $(2002,2007)$.
} 
representation or Aktionsart module, each of which is encoded differently. Here is the basic representational format for a lexical template:

predicate: [SEMANTIC MODULE $<$ lexical functions $>$ ] [AKTIONSART MODULE $<$ semantic primes $>$ ]

The rightmost hand part of the representation includes the inventory of logical structures as developed in RRG with the proviso that the predicates used as part of the meaning definition are putatively candidates for semantic primes, or else, these cannot be further decomposed. This allows us to avoid the problem of having to regard as undefinable predicates which can be further semantically decomposed, e.g. defining the predicate redden in terms of BECOME red', or popped in terms of INGR popped', or activity predicates like sing or drink in terms of do' (x, [drink' (x)]) or do' $\left(\mathrm{x},\left[\right.\right.$ sing' $\left.\left.^{\prime}(\mathrm{x})\right]\right)$. The innovation here with respect to the original RRG proposal resides in finding a systematic procedure to identify the correct prime together with a uniform framework for decomposing every predicate semantically until we arrive at the undefinable elements.

The semantic and pragmatic properties of the semantic module, as shown in the leftmost hand part of the representation, are formalized by making use of lexical functions such as those used in Mel'čuk's Explanatory and Combinatorial Lexicology (ELC) (cf. Mel'čuk 1989; Mel'čuk et al. 1995; Mel'čuk and Wanner 1996; Alonso Ramos 2002). ${ }^{10}$ These lexical functions have also been shown to have a universal status (cf. Mel'čuk 1989), something which is in keeping with our aim of providing typologically valid representations. In contrast to the use of lexical functions in Mel'čuk's work and the complete literature on the Explanatory Combinatorial Dictionary, in our approach such functions are essentially paradigmatic

\footnotetext{
${ }^{10}$ According to Mel'čuk et al (1995: 126-127), a lexical function (LF) is written as: $\mathbf{f}(x)=y$, where $\mathrm{f}$ represents the function, $x$, the argument, and $y$, the value expressed by the function when applied to a given argument. The meaning associated with an LF is abstract and general and can produce a relatively high number of values; e.g. Magn expresses intensification and can be applied to different lexical units thus yielding a high set of values:
}

$\begin{array}{llll}\text { Magn } & \text { (Engl. smoker }) & \text { heavy } \\ \text { Magn } & \text { (Engl. bachelor }) & = & \text { confirmed } \\ \text { Magn } & \text { (Sp. error) } & = & \text { craso } \\ \text { Magn } & \text { (Sp. llorar) } & = & \text { llorar como una Magdalena }\end{array}$


and capture those pragmatic and semantic parameters that are idiosyncratic to the meaning of a word, which allows us to distinguish one word from others within the same lexical hierarchy. For example, if we want to account for the semantic differences between mandar ('command'), ordenar ('order'), decretar ('decree'), preceptuar ('set up a precept'), preinscribir ('preregister') from the lexical domain of speech acts or cautivar ('captivate'), arrebatar ('seize'), arrobar ('entrance'), embelesar ('enrapture'), extasiar ('send into an ecstasy'), hechizar ('bewitch') from the domain of feeling in Spanish, we would certainly need some mechanism that allows us to discriminate and encode those meaning elements that differentiate one predicate from others. Then, we have devised a semantic module that consists of a number of internal variables, i.e. world knowledge elements of semantic structure, which relate in very specific ways to the external variables that account for those arguments that have a grammatical impact. Now, let us consider the following examples:

captar: [MagnObstr \& Culm $\left._{12[[A L L]}\right]$ know' $(\mathrm{x}, \mathrm{y}) \mathrm{x}=1 ; \mathrm{y}=2$

consider: [LOC ${ }_{\text {in }}^{\text {temp }}{ }_{1,2}$ CONT] think' $(x, y) x=1 ; y=2$

In Spanish captar ('grasp') the logical structure represents a state predicate with know' as primitive and modified by two variables $x$ and $y$. On the right hand side, the semantic module includes two parameters that encode the culmination of knowing the propositional meaning of something $\left.\left[\mathrm{Culm}_{12[[\mathrm{ALL}]}\right]\right]$ and the fact that this process has been done with great difficulty [MagnObstr]. Then, in consider, we have a two place state predicate with the primitive think' as definiens. Within the lexical domain of cognition, Faber and Mairal (1999) note two types of indefinables, know and think, that serve to define the rest of the predicates in this class. The case that concerns us here belongs to the think type and is modified by two lexical functions, [LOC in temp↔ $\left.{ }_{1,2}\right]$ and [CONT], that express duration and temporal setting (in the present). ${ }^{11}$

\footnotetext{
11 A further issue that arises is if lexical functions provide a complete catalogue of the different semantic and pragmatic parameters that are involved in the meaning definition of a word. Moreover, it would be desirable to regroup lexical functions into broader categories such that the inventory becomes more transparent. Within this context, a very recent development proposes to readapt the semantic
} 
Lexical templates are built into constructional templates, which have a more abstract nature and are largely based on Goldberg's (1995) notion of argument constructions. Argument constructions are associated with Level 1 constructional templates in the LCM, which form the core grammar module and are made up of elements of semantic interpretation that can be realized syntactically. Hence, constructional templates thus consist of sets of arguments that relate to one another on the basis of abstract predicates such as CAUSE, BECOME, MOVE, and HAVE. In the LCM we have adapted these representations to the same formalism as used in a lexical template, which means that constructional templates at this level, which are largely grounded in an Aktionsart characterization, are described by using a semantic metalanguage and an inventory of operators. As a result, both lexical templates and constructional templates are based on the same metalanguage, which makes the unification of the two formalisms a straightforward task. For example, let us see the format of the caused-motion construction:
a. $\left[\mathbf{d o}^{\prime}(\mathrm{x}, \mathrm{y})\right]$ CAUSE [BECOME *NOT be-LOC $\left.{ }^{\prime}(\mathrm{y}, \mathrm{z})\right]$
b. [pred' $(x, y)]$ CAUSE [BECOME *NOT be-LOC' $(y, z)]$

Although this construction is not very productive in Spanish, there are just a few examples like (3), where the causing subevent is a state predicate: ${ }^{12}$

$\begin{array}{llll}\text { (3) } \text { Quiero } & a & \text { María fuera de mi } & \text { casa. } \\ \text { want-PRS.1SG } & \text { OBJ } & \text { Mary out of POSS.1SG } & \text { house }\end{array}$

'I want Mary out of my house'

$$
\text { [want' (yo, María)] CAUSE [BECOME *NOT be-LOC' (María, casa)] }
$$

Recall that, as discussed in and Goldberg (1995), and in Van Valin and LaPolla (1997), the caused-motion construction, which might be well equally interpreted as a

\footnotetext{
modules of the lexical templates in terms of Pustejovsky's (1995) qualia (cf. Mairal and Cortés, in prep.; Cortés, this volume).

12 For a representation of the inchoative construction and the subjective transitive construction, we refer the reader to Cortés (this volume) and Gonzálvez-García (2008).
} 
case of the resultative construction, introduces another logical structure that focalizes a further degree of the result obtained by the state part of the lexical template. This subevent is saturated by either an adjectival or a prepositional phrase.

\section{The possible relations between verbs and constructions}

Construction Grammar approaches have postulated very general principles to account for the possible relations between verbs and constructions: for example, the Semantic Coherence Principle, the Correspondence Principle, the Causal Relation Hypothesis (Goldberg 1995:50; 61, 62), or 'coercion' and its associated principle the Override Principle (Michaelis 2003). However, these principles are too general to account for the specificities and exact conditions that actually regulate the integration of a verb's lexical entry with the construction in which it is embedded. The Semantic Coherence Principle simply states that the participant role of the verb and the argument role of the construction must be semantically compatible. The Correspondence Principle specifies that semantically salient roles must be encoded in such a way that they receive sufficient discourse prominence (that is, the principle ensures that lexical specifications and discourse structure are generally aligned). The Causal Relation Hypothesis, based on previous work by Croft (1991), states that verbal and constructional meaning must be integrated via a temporally contiguous causal relationship (e.g. sound emission verbs, such as screech in The train screeched into the station can be used to designate motion if the sound results from and occurs simultaneously with motion; cf. The dog barked into the room). Finally, the Override Principle stipulates that the meaning of a lexical item must conform to the meaning of the structure in which it is embedded. For example, in Spanish (as in English) we find that the predicates romper ('break'), cortar ('cut') and destruir ('destroy') exhibit distinct syntactic behavior in the context of the inchoative construction and the impersonal reflexive construction (see Cortés, this volume):
a. Romp-ieron
la
ventana
(con facilidad).
break-INDEFPRET.3PL DEF.F.SG
window with ease
'They broke the window easily'
b. La ventana se romp-ió (con facilidad) 
DEF.F.SG window REFLEX PASS break-INDEFPRET.3SG with ease [como por símism-a].

as.if by itself-F.SG

'The window broke easily (as if by itself)'

c. Destruy-eron el edificio.

destroy-INDEFPRET.3PL DEF.M.SG building

'They destroyed the building'

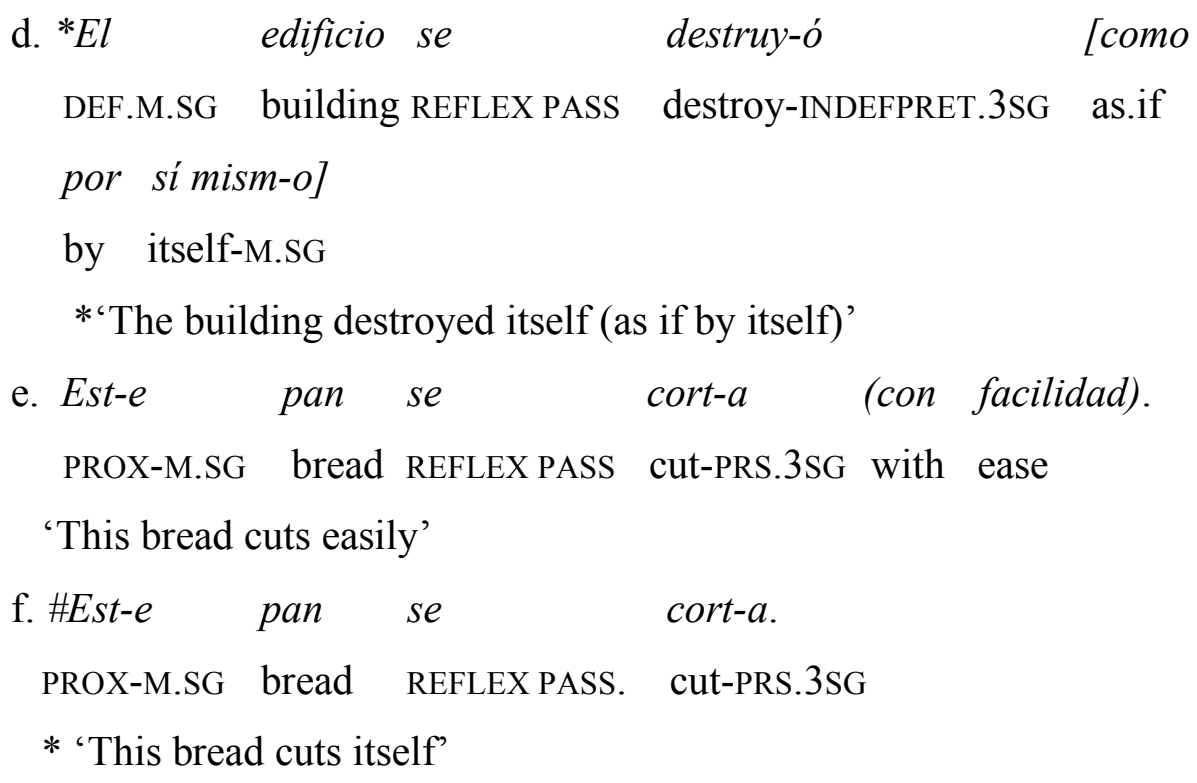

We claim that it is necessary to identify the type of elements that are part of the structure of verbs like romper or cortar, which allow the impersonal reflexive in (a) and the evaluative reflexive construction in (b). In much the same way, it is necessary to determine why a predicate like destruir blocks out a reflexive construction as shown in (d). The LCM posits two major mechanisms that account for the possible relations that are established between a verb and a construction, on the one hand, and between a constructional level $\mathrm{l}_{\mathrm{n}}$ and a higher constructional level $\mathrm{l}_{\mathrm{n}+1}$, on the other hand. One of the mechanisms, which works purely at the grammatical level, is the one we have referred to above by the label subsumption. The other mechanism, cueing, deals with inferences developed on the basis of the blueprint provided by the output of lexical and constructional integration at whatever level of representation. The two mechanisms are in turn regulated by what we have termed internal and external constraints (cf. Section 7). 


\section{The pragmatic and discourse dimensions of constructional meaning}

Functional approaches have been for some time concerned with the nature of the pragmatic and discourse dimensions of meaning. The goal of giving pragmatic adequacy to grammatical explanation influenced much of Dik's Functional Grammar, which also addressed some discourse phenomena such as topicality and focalization (cf. Dik 1997b). The more recent Functional Discourse Grammar (Hengeveld 2004; Hengeveld and Mackenzie 2006, 2008) has gone so far as to take the discourse act as the basic unit of analysis. In Cognitive Linguistics, the concern with pragmatics and discourse has guided an increasing amount of research (e.g. Langacker 2001; Otal and Ruiz de Mendoza 2007; Panther and Thornburg 2003; Ruiz de Mendoza and Pérez 2003; Steen 2005) but, in contrast to Functional Grammar, neither dimension has been made a central part of any of the existing accounts. The tendency in CL is to show that pragmatic and discourse phenomena can be accounted for by making use of the same mechanisms used for other domains of linguistic enquiry. Thus, Langacker (2001) applies the notions of profile and base, which are pervasive in grammar, to an understanding of the relationship between finite clauses and the context in which they are produced. He also contends that the basic units of discourse structure are relationships (propositions) rather than things (nominal expressions), another basic division of his Cognitive Grammar. But this treatment of discourse makes it epiphenomenal, the result of opening up attentional frames that often correspond to clauses that one after another serve to create and update a discourse space. There is no discussion of how some linguistic mechanisms serve as cues to creating conceptual connectedness, nor is there any indication of what principles regulate the creation of discourse structure. In other words, discourse meaning is not made part of a unified framework.

The LCM does aim to offer a unified approach to the pragmatic and discourse dimensions of meaning construction. In order to do so, it must accomplish three crucial tasks: one is to distinguish between different levels of non-argumental meaning; a second task consists in finding to what extent a non-argumental level of description is to be accounted for in terms of grammatical mechanisms, especially since much of the meaning at the pragmatic and discourse levels is obtained 
inferentially; the third task is to determine the principles that regulate interaction between the different layers. First, since the LCM has a constructional orientation, it focuses its attention on postulating constructions that capture in a highly conventionalized way different layers of non-argumental meaning. In the LCM argument constructions are considered part of the core-grammar level of description, or level 1, where content-bearing lexical items and predicate-argument constructions interact to produce what is normally called propositional meaning. Then, the LCM distinguishes between three kinds of non-argumental constructions: (i) level 2 or implicational constructions, which capture meaning that arises from the way the speaker interacts with the lexical and grammatical properties of utterances but does not affect the basic relationship between predicates and their arguments; (ii) level 3 or illocutionary constructions, which deal with meaning that arises from the way speakers interact on the basis of argument-predicate configurations; (iii) level 4 or discourse constructions, which deal with how the speaker creates connectedness in his speech production on the basis of all other aspects of the semantic configuration of utterances.

One interesting feature of levels 2, 3, and 4 constructions is their higher degree of idiomaticity when compared to level 1 constructions. In the case of level 1 constructions, we sometimes come across expressions that are either fully idiomatic, i.e. that admit a very low degree of elaboration or none at all, such as kick the bucket, spill the beans, beat about the bush, bear the brunt of, let the cat out of the bag, walk the second mile, and others that are midway between being idiomatic and being argumental: look someone in the eyes, make oneself at home. But even the more flexible level 1 idiomatic constructions do not match the degree of elaboration that constructions at other levels can reach. This is so because these higher-level constructions combine idiomatic elements with highly parametrizable variables. We deal with levels 2,3 , and 4 constructions in the following subsections.

\subsection{Implicational constructions}

Let us consider the following utterances:

(5) a. Who's been messing with my computer?

b. It was your son that broke the window. 
Example (5a) is a case of presuppositional construction and (5b) of focus construction. Let us deal with each construction in turn. In (5a), the speaker is bothered by the situation described at the argument structure level through a presupposition (i.e., someone has been messing with the speaker's computer). The idea that the speaker is bothered is not directly derivable from the presupposition, but rather from an implication based on the fact that no one is expected to use another person's computer without permission. But note that a similar implication may also be obtained from other related sentences that make use of the same structural configuration:

(6) a. Who's been crying the whole night?

b. Who's been reading my journal?

c. Who's been reciting Homer?

d. Who's been sitting here?

This happens because the pragmatic implication that the speaker is bothered by the situation described in the propositional structure of wh-sentences has become "entrenched" to a fairly large extent in the linguistic system. Entrenchment, as defined by Langacker (1999: 105), is a function of the frequency of association between a meaning element, whatever its origin, and any given structural configuration.

There are other related configurations that tend to carry the same meaning implication that we have observed for example (5a) and all the examples in (6):

(7) a. Where's our son been the whole night?

b. Why's he behaving like that?

c. When's that order been issued?

d. What's your sister been doing today?

All these configurations presuppose that whatever is described after the whinterrogative pronoun has actually been the case. But we can have the same meaning effect even if we make use of a non-presuppositional construction. The clearest case is provided by the What's X Doing Y? construction, discussed by Kay and Fillmore (1999): 

a. What's the child doing in the garden?
b. What's your sister doing in the theatre?
c. What's your mother doing in the kitchen?
d. What's the Prime Minister doing in China?

In all the examples in (8) there is a situation simultaneous with the time of utterance. In contrast with the presuppositional examples (5a), (6a-d), and (7a-d) the actuality of the situation is not taken for granted on the basis of a level 1 property of the construction, but rather on the basis of a default assumption whose origin is to be found in a potential pragmatic implication. If any of the sentences of the form 'What's $\mathrm{X}$ Doing Y?' is produced in a context in which it is evident to the speaker that the hearer is already aware of the situation, the only way to make them relevant is to shift the meaning interpretation from one where the hearer is being required to describe the situation to one in which the hearer needs to determine how the speaker feels about the situation. In this connection, note that sentences exploiting this construction are often interpreted as forms of calling the hearer's attention to a negative situation about which the hearer (or even someone else) would have been expected by the speaker to do something or as ways of complaining about the situation if fixing it is beyond other people's ability. Compare:
a. The child is up to something in the garden.
b. Your sister is again in the theater with that boyfriend of hers.
c. The doctor told you your mother should have full rest.
d. The Prime Minister was not supposed to go to China.

Following the interpretive rationale specified above, sentences (9a), (9b), and (9c) would have a default interpretation as requests for remedial action. Sentence (9d) would be a complaint. However, we may find contexts where the first three sentences are either pure complaints where the speaker does not expect the hearer to act in any way or a conceptual combination of complaining and requesting for remedial action. For example, for (9b), it is possible to think of a context where the speaker feels that the hearer has no possibility of doing anything to prevent his sister from dating her boyfriend. Then, (9b) would be understood as a complaint and nothing else. But if the 
speaker feels the hearer could stop the situation, then (9b) would also be a request for action. These observations will be taken up again later on, when we discuss level 3 meaning constructions. For the time being, it is sufficient to note that the call for action and its associated complaint interpretation are only possible because of a highly conventionalized (or entrenched) meaning implication that is produced at level 2 through a constructional mechanism. We also observe that sentence (5a) and the sentences in (6) and (7) above give rise to similar level 3 interpretations.

A different case of level 2 construction is provided by focus constructions, like (5b). Focalization of a level 1 constructional element is a widespread phenomenon in many languages. Dik (1997b) has discussed what he calls focus constructions in a number of unrelated languages. Focalization can be achieved through a variety of linguistic mechanisms involving cleft structures, intonation, accentual prominence, and reduplication. Each mechanism has the function of presenting part of the information of the sentence as more relevant than the rest either because it is new or because the speaker thinks it is worthy of note for the hearer. For example, in $(5 b)$ we can have a situation where both speaker and hearer are aware that the hearer's son broke the window. In this context the piece of information that receives prominence is intended to emphasize the hearer's son's responsibility and probably the hearer's own responsibility to deal with the situation as needed on the basis of the established socio-cultural patterns. But the same information could be totally new to the hearer, in other contexts, and be therefore taken as an initial call of the hearer's attention to deal with the situation. Since focus constructions are forms of restructuring level-1 information in a way that it shows how the speaker interacts with it, the LCM deals with them at level 2.

\subsection{Illocutionary constructions}

Level 3 constructions give rise to conventionalized illocutionary meaning. Here the LCM departs rather drastically from functional models such as those propounded by Halliday (1994) (see also Halliday and Matthiessen 2004) and Dik (1997b) and comes somewhat closer to some proposals within Cognitive Linguistics, especially Stefanowitsch (2003), Thornburg and Panther (1997), Panther and Thornburg (1998, 2003), and Panther (2005), although there are still some crucial differences. Halliday and Matthiessen (2004: 107) do not think of speech act meaning or illocutionary 
meaning as a meaning dimension apart from grammar. In their view, the clause can be seen as a grammatical unit that combines meanings of three different kinds: ideational, interpersonal, and textual, each of them corresponding to one of the general functions of language. Each meaning dimension presents the clause from a different perspective: as representation (ideational meaning), as exchange (interpersonal meaning), and as message (textual meaning). Speech act meaning is thus treated - with mood, polarity, and modality systems - as a part of the clause-asexchange dimension of grammar. More specifically, it is seen as a matter of giving or demanding either information or so-called "goods-\&-services". This activity results in four basic speech functions and their associated responses (see Table 2).

\section{[Table 2 near here]}

Halliday and Matthiessen's analysis is faced with two important challenges. First, while it is easy to accept that we can make use of language to give or demand information and to demand "goods-\&-services", it is not at all clear in what way we can give "goods-\&-services" by means of language. Rather, what we do is indicate that we have the desire or the willingness to give "goods-\&-services", as is the case with offers and promises. The system is therefore not as symmetrical as proposed by Halliday and Matthiessen. ${ }^{13}$ Second, there is no indication in this account of how we can deal with non-primary speech functions (requesting, begging, promising, warning, threatening, condoling, boasting, among many others that have been discussed in the traditional speech act literature) and their associated responses, which are not necessarily the same as the ones proposed for the primary speech functions. For example, while it might be argued, following Halliday and Matthiessen's rationale, that promising is, like offering, a way of "giving goods-\&-services", it would not be reasonable to argue that we can "accept" a promise. Promising is more naturally followed by an expression of gratitude as a response:
A: OK, you shall have the new bicycle you wanted, I promise
B: Great! Thank you so much! (cf. \# Yes, please, do!).

\footnotetext{
${ }^{13}$ A similar point is found in Fawcett (1980), who remarks that offers are normally realized nonlinguistically but are often accompanied by an information-giving utterance.
} 
Note that when we find an expression of acceptance following a promise, the scope of the response is not the actual promise but the future action involved in it:
(11) A: OK, I'll buy you the bicycle you wanted, I promise.
B: Yes, please, do!

B's response in (11) is not an expression of acceptance, but a form of encouraging his interlocutor to act as specified in his speech turn, i.e. to live up to his promise.

Or consider expressive speech acts such as congratulating, thanking, apologizing, condoling, and boasting. They are forms of giving information while expressing the speaker's attitude to it. However, the expected responses are not generally those of acknowledgement or contradiction:

(12) A: You gave a great talk.

B: Thank you (\#Yes, I did) (\#No, I didn't).

(13) A: We are grateful that you are serving your country.

B: It's an honor (\#Yes, you are/\#Yes, I am) (\#No you're not/\#No, I'm not).

(14) A: I'm sorry I forgot to call you.

B: That's fine. Don't worry (\#Yes, you are/\#Yes, you did) (\#No, you're not/\#No, you didn't).

(15) A: I'm sorry your mother died.

B: Thank you (\#Yes, you are/\#Yes, she did) (\#No, you're not/\#No, she didn't).

(16) A: I'm the best in town.

B: Yes, you are / No, you're not.

Except for the act of boasting in (16), which can be acknowledged or contradicted, the rest expect responses to the first speaker's attitude in the form of thankfulness (for congratulating, condoling) or acceptance (thanking, apologizing). As is evident from 
the odd responses between brackets, expressive acts are not very sensitive to responses based on the non-attitudinal content of the initiating turn. In fact, such responses, when they take place, break politeness expectations. Thus, in (12), the acknowledging answer (Yes, I did) is a form of inappropriate boasting, and the contradicting response (No, I didn't) of humility. In (13), we can acknowledge or contradict the content of the matrix or of the subordinate clause. If the response refers to the matrix clause, which carries the explicit illocutionary predicate, the meaning effect is one of pragmatic inadequacy: Yes, you are is likely to be interpreted as ironical (the second speaker believes the opposite of what he says) as a way of resolving the absurdity of reasserting the truthfulness of the first speaker's expressed attitude; No, you're not is offensive since it directly contradicts the sincerity condition of the explicit illocution. Similar considerations hold for (14) and (15), where reaffirming the matrix clause may readily be taken as ironical and negating the matrix clause suggests insincerity. If, on the other hand, the response refers to the subordinate clause, the expression of acknowledgement could be acceptable as a form of self-assurance, while the negation could be taken as a rather inappropriate way of showing humility or as a (probably impolite) contradiction of the reason for the expression of thankfulness. Here, examples (14) and (15) work differently. Thus, in (14) reaffirming the subordinate clause of an explicit apology (Yes, you did) is a way of manifesting that the apology may not be accepted. This is so because of the conceptually iterative character of the reaffirmation: if an apology is accepted, there is forgiveness, but reminding the offender again about his offence suggests lack of forgiveness. In condolences, however, reaffirming the subordinate clause is tantamount to a reiteration of the conditions that cause sorrow, which may suggest that the expression of sympathy will not be useful to soothe the emotional pain or that there is no such pain, so the condolences are not really necessary. In turn, negating the subordinate clause of an apology directly renders the apology unnecessary, since it is the same as saying that the conditions that motivated the apology are not valid. The same applies to the negation of the subordinate clause in (15), where the speaker rejects the validity of the conditions that would call for condoling.

Since the range of possible responses to variants of the primary speech functions is very complex, Halliday and Matthiessen's account needs to be improved. In our view, a possible improvement is found in the account by Dik (1997b), who observes that, according to typological data (Sadock and Zwicky 1985), most 
languages code four basic speech acts, i.e., statements, questions, commands, and exclamations. Except for exclamations, each basic speech act corresponds to one of the widely recognized sentence types: declarative, interrogative, and imperative. Exclamations are obtained by applying special suprasegmental features to sentences of any of the three basic types. Human languages then have special grammatical mechanisms to derive other illocutions from the basic ones. In English, it is possible to convert declarative, interrogative, and imperative sentences into requests by adding please: Please, I can't stand that noise!; Pass me the salt, please!; Can you please swim?. Declaratives can be converted into questions by means of a tag: She's the best in class, isn't she? An imperative can become an exclamation through the adequate combination of stress and intonational features: See who's COMING! Dik also admits the existence of non-grammatical, pragmatic mechanisms to derive illocutionary meaning, which explain, for example, why I'm thirsty is likely to be interpreted as a request for water. However, there are two problems with the idea of derived illocutions. One has to do with the fact that the degree of necessity of a conversion device like please in order to disambiguate a given structural configuration can vary. Thus, please is more necessary in (17a) than in (17b) below for a request interpretation. And sometimes, for the same structural configuration (e.g. a Can You sentence), the conversion device cannot be used, as in (17c).
a. Can you swim? > Can you swim, please?
b. Can you listen to what I'm saying (please)?
c. Can you see the island from here? > *Can you please see the island from here?

The other problem is related to the fact that many non-basic conventional illocutions seem to be obtained directly, without any derivational (whether grammatical or pragmatic) activity:
(18) a. Can't you be quiet for a minute?
b. Won't you help me at all?
c. Shall I put the light on?
d. You shall leave tomorrow.
e. Why don't you buy that book? 
These observations strongly suggest that grammar is capable of coding speech act meaning directly by developing entrenched meaning-form associations to that effect. For this reason, the LCM postulates the existence of level-3 constructions capturing conventionalized illocutionary meaning. In the LCM a Can You structural configuration is potentially ambiguous between two interpretations, one as a question about ability and the other as a request for action. Each interpretation crucially hinges upon the activation of a different construction: the polar interrogative construction, whose Aux-NP constituents can be realized (and thus parametrized) by can you; the Can You request construction, where can-you is idiomatic. In Dik's approach adverbs like please or kindly are illocutionary converters. For example, please can convert any basic illocution into a request (Dik 1997b: 246):
a. Can you pass me the salt, please? (Interrogative > request)
b. Please, John, stop tickling me! (Imperative > request)
c. Please, John, it's broad daylight! (Declarative > request)

In our approach, devices like please and kindly are optional elements of the request construction and have the function of mitigating the directive force of the construction or of urging the addressee to act in the way described by its non-idiomatic elements. Mitigation effects can also be captured through other mechanisms, like the substitution of could or would for can in (19a), which has no effect on the overall request value of the resulting utterances (cf. Would/could you pass me the salt?), but simply affects their degree of politeness and/or formality. Since idiomatic constructions admit a degree of variation in their non-parametrizable elements, we consider will you/would you/could you/do you think you could forms as varieties of the same construction. In general, we will not postulate the existence of a completely different illocutionary construction provided that the variation of the idiomatic elements in it is not open-ended and that the variation does not bring about changes in the illocutionary status of the configuration. 


\subsection{Discourse constructions}

Discourse constructions capture the meaning implications of discourse relations, i.e. those relations that underlie discourse coherence. Discourse coherence is a very complex phenomenon all of whose intricacies can hardly be addressed in a short space. The phenomenon involves a rich network of principled connections between the various levels of linguistic analysis, thus accounting for the potential of some linguistic mechanisms to organize discourse while specifying in what ways discourse activity may constrain certain semantic and pragmatic choices. Although the LCM takes into account these connections (cf. Otal and Ruiz de Mendoza 2007), in this section we will restrict our discussion to the question of how we interpret the meaning of a sentence in the light of the meaning implications (at whatever level) of other sentences within the same communicative event. This understanding of discourse activity is just a development of the basic insights provided by early discourse analysts such as Winter (1982), Hoey (1983), and Longacre (1972) on so-called clausal or interclausal relations. The difference is that, in the LCM, discourse connections go beyond what is signaled through linguistic mechanisms. Thus, the model admits, as we have noted in previous sections, the possibility of interpreting meaning at any level through linguistically-cued inferences. At the level of core grammar, linguistic cueing results in explicature derivation. At the other levels it results in inferred implicatures, illocutionary values, or discourse relations.

As was mentioned in the introduction section, the LCM focuses much of its attention on finding out what the different levels of linguistic description and explanation have in common. Many of the meaning relations at the discourse level can be found at other levels. This observation is not entirely new. Beaugrande (1980: 37) made a similar point with respect to cause-consequence relations, which can be inferred as in (20a) below or made explicit as in (20b):
a. Peter burned the book. He didn't like it.
b. Peter burned the book because he didn't like it.

In this view, the semantic classification of complex sentences would be a reasonable guide to a classification of discourse relations of coherence. Here, we find Halliday and Matthiessen's (2004: 378) distinction between elaborating, extending, and 
enhancing -the three logico-semantic relations in the clause complex- an adequate starting point. In elaboration, one clause expands another by addressing part of it in greater detail (e.g. restating, commenting, specifying, or exemplifying the relevant part). In extension, a clause is expanded by another clause that adds a new element, gives an exception, or offers and alternative. In enhancement, a clause is expanded by qualifying it with some circumstantial feature of time, place, cause, or condition. These three relations are general labels for more specific clause-complex relations that have been discussed by Halliday and Matthiessen in some detail. In our view, many, if not all, of these relations parallel discourse relations. For the purpose of illustration we supply in Table 3 a tentative list of discourse relations that can be related to some of the categories discussed by Halliday and Matthiessen. ${ }^{14}$

\section{[Table 3 near here]}

The list of relations in Table 3 is by no means exhaustive. More relations can be added and some of the relations that have been identified can be further refined or subdivided. For example, we may have contrastive relations, usually signaled by however, but, nevertheless, which are a form of extension: John was born in New York; his wife is from Texas (cf. John was born in New York but his wife is from Texas). We can also treat some forms of implicit comparison as cases of extension: He is careless; his partner is careless too (cf. He is careless, and so is his partner). And we may distinguish between at least two kinds of alternation relation: one where we have contrast (contrastive alternation), as in Either you win or you lose; another one, where the two alternates are not necessarily antithetical but can be complementary (complementary alternation): No one insulted him or did physical harm to him. Finally, as recognized by Halliday and Matthiessen (2004: 411) themselves, time relations can be of at least two kinds: temporal sequence (First he killed the cat, then he buried it), or temporal overlap (Tony proposed to her while she was on her knees cleaning a toilet).

As is evident from Table 3 , discourse relations can be signaled linguistically or left for the addressee to infer. In the first situation, we have discourse

\footnotetext{
14 For a more fine-grained analysis of discourse semantic relations from a systemic perspective see Martin (1992); see also Butler (2003, part 2, chapters 3 and 4) for an overview of this area of enquiry.
} 
constructions, while in the second we have cued inferencing, just as is the case with the rest of descriptive/explanatory levels of our model and as should be expected on the basis of the equipollence hypothesis. It must be borne in mind that discourse constructions vary in their degree of specificity. A case in point is the well-known $\mathbf{X}$ Let Alone Y construction, discussed by Fillmore, Kay and O'Connor (1988). In our view, this construction is a specific case of the complementary alternation construction involving two non-antithetical alternates (which in practice may be argued to shade off into cases of addition). Compare:
(21) a. I won't eat that garbage; and I won't pay for it.
b. I won't eat that garbage, nor pay for it.
c. I won't eat that garbage, let alone pay for it.

For example (21a) there is a strong default interpretation: the speaker dislikes the food that someone is trying to sell him and is not willing either to eat it or pay for it. Example (21b) has the same interpretation, but makes explicit the fact that the two clauses are complementary alternates through the use of the complementary alternation construction (not X nor $\mathbf{Y}$ ). Now, in many contexts both (21a) and (21b) may carry an additional implication: the idea that the speaker finds it outrageous to pay for such as bad quality food as he is being offered. In connection with this implication, there is still another one: that he is much less willing to pay for the food than to eat it. These two related implications are made explicit in (21c) through the use of the 'X Let Alone Y' construction. Since this construction conveys a broader range of meaning implications than the complementary alternation construction, we consider it a specific case of the latter.

According to Fillmore, Kay and O'Connor (1988), in the 'X Let Alone Y' construction, there is an entailment relationship between the elements $\mathrm{X}$ and $\mathrm{Y}$ such that $\mathrm{X}$ either expresses or implicates a negative situation and $\mathrm{Y}$ is considered less likely to happen than $\mathrm{X}$. Since the constraints on the $\mathrm{X}$ and $\mathrm{Y}$ elements do not restrict their realization to a closed class of items (i.e., the number of possible instantiations is limitless), $\mathrm{X}$ and $\mathrm{Y}$ are constructional variables. In contrast, the coordinating conjunction joining $\mathrm{X}$ and $\mathrm{Y}$ has to be chosen from among a closed set of options, such as much less, not to mention, and never mind. The coordinating conjunction is thus a non-variable element of the basic ' $\mathrm{X}$ Let Alone $\mathrm{Y}$ ' construction. Note that the 
use of one or another conjunction does not affect the meaning entailments described above:

(22) a. I won't eat that garbage, much less pay for it.

b. I won't eat that garbage, not to mention pay for it.

c. I won't eat that garbage, never mind pay for it.

Second, observe that there is a construction that is apparently the converse of ' $\mathrm{X}$ Let Alone Y'. Consider:

(23) a. He isn't a skilled worker; he's not even an apprentice.

b. He isn't an apprentice, let alone a skilled worker.

The contrast between (23a) and (23b) points to a preservation of the general constructional constraints on the $\mathrm{X} / \mathrm{Y}$ variable elements of the ' $\mathrm{X}$ Let Alone $\mathrm{Y}$ ' configuration in $\mathbf{Y}$ not even $\mathbf{X}$ : in both constructions $\mathrm{X}$ is negative and $\mathrm{Y}$ is less likely to be the case than X. However, there is a clear difference between the constructional presuppositions: in (23a) the emphasis is on the claim that the protagonist's skills are worse than those of an apprentice; in (23b) the emphasis is on negating the presupposed addressee's assumption that the protagonist could be a skilled worker. This difference explains why it is odd to convert any of the examples in (22) into a ' $Y$ not even $X^{\prime}$ format:

(24) \#I won't pay for that garbage, not even eat it.

The reason for this oddity is to be found in the fact that if the speaker-protagonist is not willing to pay for the bad-quality food, it is only natural that he will not want to eat it. So, putting the emphasis on the natural consequence, which is already implied by the first clause, is absurd.

Since the meaning implications of (23b) differ to a significant extent from those of the ' $\mathrm{X}$ Let Alone $\mathrm{Y}$ ' configuration and its variants, we will assign $Y$ not even $\mathbf{X}$ an independent constructional status. However, since there is a degree of overlap between the two constructions and both can be considered specific cases of the more 
generic complementary alternation construction, we will regard ' $\mathrm{X}$ Let Alone $\mathrm{Y}$ ' and 'Y not even $\mathrm{X}$ ' as sister constructions.

Another discourse construction that deserves some attention because of its large degree of specificity is Just Because X Doesn't Mean Y or its variant Just Because X Is No Reason to Think Y (Holmes and Hudson 2000; Bender and Kathol 2001; Weilbacher and Boas 2006). This construction is a specific case of the general causative construction that parametrizes evidence-conclusion relations. Let us compare the following sets of sentences:

(25) a. Just because it's digital, doesn't mean it sounds good.

b. It is digital, but this doesn't mean it sounds good.

c. It doesn't have to sound good simply because it is digital.

The context for the examples in (25) is a warning about the loss of audio quality when songs are converted from $\mathrm{CD}$ to $\mathrm{mp} 3$ format. The speaker presupposes that the hearer believes that digital formats for sound are better than more traditional audio formats and casts doubt on that assumption. The 'Just Because X Doesn't Mean Y' construction, used in (25a), indicates that the second constituent (captured by the $\mathrm{Y}$ variable) does not necessarily follow from the first. This meaning effect can also be obtained by a discourse implication, as in $(25 \mathrm{~b})$, or by expressing the central constructional meaning effect explicitly through a more general causative construction, as in $(25 \mathrm{c})$.

There are other ways of parametrizing evidence-conclusion relations that make use of the discourse connectors so and after all:

(26) a. It is digital; so it must sound good.

b. It sounds good; after all, it's digital.

The $\mathbf{X}$ So $\mathbf{Y}$ and $\mathbf{Y}$ After All $\mathbf{X}$ patterns are converses of each other. The former expresses the evidence first and then the conclusion that follows. The latter expresses the conclusion and then the evidence on which it is based. The meaning effects associated with each pattern are slightly different. Thus, (26a) gives prominence to the conclusion, while (26b) emphasizes the evidence. The same effects hold in the case of the negative counterparts of (26): 
Like the examples in (26), (27a) and (27b) explicitly deny the presupposition that we find in (25a) that the speaker believes that digital formats are better than traditional analogical audio. As in other cases, these discourse connections may be obtained inferentially, as in (28a) and (28b) below:

(28) a. It can't sound good; it's not digital.

b. It's not digital; it can't sound good.

These are examples of cued inferencing at the discourse level. Note that the general default use of can't as a modal auxiliary indicating a logical deduction exhibits a strong potential to act as a cue for the preferred interpretation of the whole utterance in terms of the evidence-conclusion pattern. ${ }^{15}$ Note that without this level-1 grammatical pointer, the inferential process would be less constrained from a discourse perspective:

(29) a. It doesn't sound good; it's not digital.

b. It's not digital; it doesn't sound good.

The examples in (29) work better as ways of realizing a general cause-effect relation than an evidence-conclusion pattern:

(30) a. It doesn't sound good because it's not digital.

b. It's not digital, that's why it doesn't sound good.

\footnotetext{
${ }^{15}$ Of course, it is also possible to have a non-default interpretation of can't in terms of capacity (i.e. 'it doesn't have the capacity to sound good'). In this case, the sentence It can't sound good would act as the effect element of a cause-effect pattern ('it can't sound good because it's not digital'). In either situation, a relevant part of the inferential process at the discourse level is guided by lexicogrammatical cues that act in one way or another depending on complementary contextual cues that help to determine the value of the modal auxiliary.
} 


\section{Cognitive constraints on meaning construction: cueing and subsumption}

Meaning construction in the LCM revolves around two key processes, cueing and subsumption. The former is linguistically very economical since it leaves it up to the addressee to determine in what way a message should be interpreted at any level of meaning construction. It may also be a communicative strategy to avoid the responsibility of being explicit. But it can sometimes be risky and lead to misinterpretation that has to be solved on the basis of repair and meaning negotiation strategies (see Ruiz de Mendoza and Otal 1997; Otal and Ruiz de Mendoza 2007). We consider each process in turn.

\subsection{Cued inferencing}

As has been noted throughout our discussion, cueing or cued inferencing is a way of constraining interpretation on the basis of linguistic clues. We have seen how cued inferential activity takes place at the level of discourse relations in our brief discussion of (28a) and (28b) in the previous section. We have parallel situations at the other three levels. Let us first deal with cued inferencing at the core grammar level or level 1. Take the following utterances:

(31) a. We are all ready now [for the party].

b. I certainly will [attend the meeting].

c. The president has finished [speaking].

d. They have just started [singing].

The examples in (31) are all cases of so-called 'underdetermined' linguistic expressions, i.e. expressions that can only make full sense if completed with contextual material. The study of underdetermined expressions has a long tradition. In the philosophy of language, Frege discussed the notion of sense completers (see Perry 1977) in relation to his distinction between sense and thought, where the former, which was guided by the structure of language, could be incomplete, while the latter had a truth value and was therefore complete. The items between square brackets in each of the examples in (31) would be clear cases of sense completers, 
since without them it is impossible to assign a truth value to any of the sentences to which they apply. For example, if for (31a) to be true it is necessary that the protagonists are ready for a party, then simply saying that they are ready in general will not make the sentence true. In pragmatics, Frege's sense completers are not treated as mechanisms to obtain the truth-value of an incomplete sentence, but rather as contextually-derived information that is necessary to obtain the meaningful interpretation of an utterance. Different authors have used different names for this process of filling in implicit contextual information: saturation (Récanati 1989), completion (Bach 1994), and enrichment (Sperber and Wilson 1995). But what is important is the fact that this process of filling in missing information is regarded by these scholars as an inferential one and, we may add, a constrained one too: the language user needs to find adequate contextual information that matches the requirements imposed by the expressed utterance. Note that such requirements are largely constructional rather than based on lexical projection. Thus, in (31a), the Y element in the $\mathbf{X}$ Be Ready $\mathbf{Y}$ construction has a syntactically optional complement expressing the event or activity for which arrangements have been made either on the basis of a 'for+NP' structure or a to-infinitival clause. Other options are excluded (cf. *He was ready going to the party/*He was ready for going to the party). This constructional character of ' $\mathrm{X}$ Be Ready $\mathrm{Y}$ ' is further reinforced by other formal features of this configuration, such as the reluctance of the verbal predicate to appear in the progressive form $(*$ We are being ready for the party). In turn, modal constructions allow for the elision of easily recoverable previous textual material, as in (31b). Finally, (31c) and (31d), which omit the non-finite verbal complement, are based on two converse phasal aspect constructions: (31c), which signals the end point of an action, is egressive; (31d), which signals the initial point of an action, is ingressive.

There are other ways of cueing inferences at level 1. Consider the examples in (32), (33), and (34) below:

(32) a. Something [bad] has happened.

b. Your father [habitually] drinks [alcohol].

c. She has a [higher-than-normal body] temperature.

a. My sister has [exactly] three children. 


\section{b. There were [approximately] three hundred thousand demonstrators. \\ c. John and Alex went to the city museum [together].}
a. Nice day!
b. You there!
c. Morning!
d. Look out!

Carston $(2002,2004)$ has discussed examples like these as different forms of free enrichment, a term which suggests that the completion or specification process is not guided by the linguistic structure of the message. The first form is illustrated by the examples in (32), where a literal (i.e. descriptive) reading of each utterance yields an obvious truth: events happen, humans drink liquids, and people who are alive have some body temperature. But, interpretively, each of the utterances in (32) is fully meaningful. The second form of free enrichment, which is illustrated by the examples in (33), holds for utterances whose basic conceptual layout contains elements that need to be spelled out in greater detail. Note that the bracketed specifications are default interpretations: (33a) would be true too if the speaker's sister had more than three children; (33b) would be just as true if there were exactly three hundred thousand demonstrators; (33c) could also apply to a situation in which John arrived at the museum first and Alex some time later. Finally, the third form of free enrichment is illustrated by so-called subsentential utterances, which are the equivalent of what Halliday and Matthiessen call minor clauses. Clauses of this kind are different from elliptical clauses in which the elided elements are presupposed either on the grounds of the preceding linguistic context, as in question-answer pairs, or of the grammatical structure of the explicit elements (Seen Fred? [Have you seen Fred?]). Minor clauses do not have a verb (or another form of predicator) and they typically realize such functions as exclaiming, calling, greeting, and alarming, as illustrated respectively by each of the examples in (34). They may also be used presentatively (e.g. Mr. Jones, uttered by way of introduction of Mr. Jones) or even indexically (e.g. A stork!, uttered with surprise by a small child as he points at the bird). The overall function of minor clauses is to call the addressee's attention to some entity, situation, or event, while elliptical clauses are simply ways of avoiding repetition of recoverable material. 
Cued inferencing at levels 2 and 3 take the form of traditional implicatures and illocutionary force respectively. In the LCM implicatures are seen as the result of affording access to low-level situational models by mentioning a relevant part of them (cf. Ruiz de Mendoza 2007). This is in fact a metonymic operation:

\section{Mary: Is your tooth still hurting?}

Fred: Finally, I called the dentist.

The brief conversational exchange in (35) is based on every-day knowledge that we have about 'going to the dentist'. By mentioning a relevant part of the frame, we give the addressee access to the whole frame: in (35) we are explicitly told that the second speaker called the dentist, and we interpret that the second speaker made an appointment, that he went to the dentist's office, that the dentist took care of his dental problem, and that the tooth is probably not bothering the speaker any more. In Frame Semantics it would be argued that 'going to the dentist' is a frame, in much the same way as going to school, visiting a museum, dining at a restaurant, buying and selling, and the like. The notion is equivalent to constructs like scripts and scenarios postulated in the 1970s by a number of Artificial Intelligence workers that elaborated computer programs capable of generating inferences within restricted worldknowledge domains (e.g. Schank and Abelson 1977). In the LCM, situational frames are regarded as low-level situational models, to be differentiated from high-level situational models and from non-situational models. Both low-level and high-level situational models can be exploited metonymically in order to produce low-level and high-level implicated meaning. The former is the basis of traditional situation-based implicatures; the latter is traditional illocutionary meaning. Thus, we can compare the interpretation process for (35) with the one for (36) below:

\section{(36) Mary: I'm terribly thirsty.}

Fred: I'll get you something to drink.

When people are thirsty, they usually look for something to drink. In every-day life we encounter hundreds of situations in which people face problematic situations and try to find ways to solve them. In many of these situations, people simply expect other people to be obliging and help them to solve their problem. On the basis of previous 
work by Pérez and Ruiz de Mendoza (2002), Ruiz de Mendoza and Baicchi (2007) have captured the essentials of these cultural expectations in part of a complex highlevel cognitive model, which they call the Cost-Benefit Idealized Cognitive Model. The subdomain that applies to the interpretation of (35) as a request reads as follows (Ruiz de Mendoza and Baicchi 2007: 111):

If it is manifest to $A$ that a particular state of affairs is not beneficial to $B$, and if $A$ has the capacity to change that state of affairs, then A should do so.

Mary's strategy in (35) is to make Fred aware that she has a problem, in the hope that Fred will act as is to be expected on the basis of cultural convention and solve her problem. In acting this way, the first speaker affords access to the whole subdomain by making explicit the part where a non-beneficial situation is affecting her. This is a metonymic exploitation based on a high-level situational model, which yields an interpretive situation that parallels the one we identified for implicatures, the only difference being the greater degree of genericity of the situational model in the case of illocution.

\subsection{Subsumption}

Subsumption is a stepwise meaning production mechanism that consists in the principled incorporation of lower levels of semantic structure into higher levels of syntactically-oriented structure (Ruiz de Mendoza and Mairal 2007a, 2008a; Mairal and Ruiz de Mendoza 2008). Subsumption is a constrained process that takes place at all levels of meaning derivation. At the level of core grammar (Level 1), internal constraints specify the conditions under which a lexical template may modify its internal configuration or the conditions for (part of) a constructional template to be realized by a given lexical item. They take the form of licensing or blocking factors that depend on lexical class ascription, on lexical-constructional compatibility, and on either predicate or internal variable conditioning of external variables. External constraints, in contrast, do not relate to the internal adaptation of lexical items to constructions, but rather to potential changes in the global category ascription of a lexical item when subsumed into a construction. In order to better appreciate the 
difference between the two kinds of constraint, let us consider the following sentences:

(37) a. The audience laughed the actor off the stage.

b. She drove me into a depression.

Sentence (37a) illustrates the caused-motion construction, which has been extensively discussed by Goldberg $(1995,2006)$. The construction typically requires the use of a caused-motion verb, as in She blew the napkin off the table, He pushed me into the room, They shoved me out of the car, but there many examples of the construction where motion is expressed but no motion verb is used, as in (37a). Other examples are possible:

(38) a. She could smile him into abject submission.

b. Finally, I could feel I was listened into existence.

c. Sandra stared him into silence.

d. His colleagues shouted him out of the lecture hall.

e. She winked him into her bedroom.

In other cases, we can make use of a caused-motion verb but there is no real motion. One example of this is (37b). Other examples are easy to come by:

(39) a. How will he get us out the quagmire of war?

b. His policy is pushing our cause into oblivion.

c. The discovery threw her into a state of great excitement.

d. Hard thumping sounds pulled him out of his thoughts.

e. When sin brought me into trouble, I found my refuge in you.

So, we have two different situations: one in which we need to account for the incorporation of a non-motion predicate into a constructional configuration that requires a motion predicate; another in which caused motion is figuratively used to express a change of state. In the LCM, the first situation, which involves the subcategorial conversion of verbal predicates, is considered a case of external constraints, and the second situation, which has to do with modifications in the 
internal configuration of lexical and constructional templates, is a matter of internal constraints on lexical-constructional subsumption. Let us discuss each kind of constraint in greater detail.

Consider again example (37a). The verb laugh is basically intransitive (e.g. Today we laughed a lot during the performance), but it can be used transitively by taking an oblique complement (e.g. Why are you laughing at the actor?). But this transitive use of laugh is qualitatively different from other forms of transitivity where the verbal action has a direct effect on the object, as in break, hit, kill, kiss, pull, push, and put, which we will refer to as effectual action verbs. In English this difference between effectual and non-effectual transitivity is marked by the use of a nonprepositional versus a prepositional object. Now, effectual action verbal predicates mark some form of cause-effect connection between agent and object. In some cases, the effect is an inherent part of the meaning of the predicate (e.g. killing results in death); in others, the effectual predicate only codes a very generic form of effect that is open to further specification by means of explicit resultative predicates, some of which express motion. Consider:

(40) a. The child broke the vase [into pieces].

b. He hit the ball [off the field].

c. She kissed him [unconscious].

d. He pulled me out of the car.

e. She pushed me into the pool.

f. She put the book back on the shelf.

Note that the greater the genericity of the effect coded by the verbal predicate, the greater the need for a resultative complement. Thus, while the resultative specification is fully optional in (40a-c), it is slightly less so in (40d-e) and it is obligatory in (40f). Observe additionally that in (40b) and (40d-f) the result of the action is motion. In (40a) and (40c) the result of the action is a state, which in (40c) is expressed through a resultative adjective, whereas in (40a) it is expressed by means of figurative motion. It is evident from all these observations that the caused-motion construction requires effectual action verbal predicates whose effect component can be made explicit in the form of a prepositional complement expressing motion. This would mean that noneffectual action predicates (e.g. die, slide, flow) and effectual action predicates that 
code a specific effect (e.g. kill, poison, hurt) are not adequate candidates to take part in the construction. If this is the case, then what allows a verb like laugh to be used in the caused-motion construction? In our view, the answer lies in the possibility of treating this verb, which is not an effectual verb, as if it were an effectual verb (cf. Ruiz de Mendoza and Mairal 2007b). Obviously, this special treatment of laugh is metaphorical in the sense given to this term in Cognitive Linguistics (Lakoff 1987; Lakoff and Johnson 1980, 1999); that is, there is a mapping or set of correspondences between two conceptual domains whereby one of the domains, the source, is used to think and reason about some aspects of another domain, the target. In the metaphor from an effectual action to non-effectual actions we treat actors of various kinds as if they were effectors, and goals as if they were effectees (i.e., direct objects of the effectual action). The metaphor can thus be applied, as a licensing factor, when verbs like laugh and others like those in the examples in (38) above are subsumed into the caused-motion construction, which requires an effectual predicate without an in-built result of the action. Note, in this connection, that in this subsumption process the object loses the grammatical mark of obliqueness. This mark is necessary outside the construction. Consider, in contrast to the correctness of the examples in (38) above, the impossibility of those in (41) below, where the constructional indicators of caused-motion have been removed:
a. *She could smile him.
b. *They listened me.
c. *Sandra stared him.
d. *His colleagues shouted him.
e. *She winked him.

There are other possible metaphors constraining grammatical conversion phenomena motivated by lexical-constructional subsumption:

(42) a. We all drank (a lot of alcohol).

b. We all drank (a toast) to John Rambo and the United States of America.

(43) a. The cook separated the yolk from the white. 

a. Mary cut the bread.
b. Mary cut at the bread.

First, let us consider example (42b) in relation to (42a). The use of drink in (42a) is its regular use as either an intransitive or a transitive predicate specifying the object of the action. In (43b), however, drink is adapted to make it part of the benefactive construction. This construction borrows part of its makeup from the ditransitive construction (e.g. We gave a machine gun to John Rambo), which in turn makes use of caused-motion constructional elements (cf. We sent/threw a machine gun to John Rambo 'We caused a machine gun to move to John Rambo's location by sending/throwing it'). In so doing, the benefactive construction treats institutionalized activities like drinking a toast, erecting a building, painting a picture, reciting a poem, among others, as transfers of possession that benefit the receiver. This is again metaphorical thinking. Interestingly enough, the idea of benefit is the result of a default implication - grounded in experience - from what we know about objects being transferred: when the object is at its destination, the receiver gains control of it (usually in the form of possession). So the roles of destination, receiver, and controller (or possessor) are conflated in our experience (cf. Lakoff and Johnson 1999, for other examples of experiential conflation and their role in metaphor).

Example (43b) is a case of the reciprocal construction: the source domain is the domain of companionship (cf. We didn't separate John and Mary), and the target is the domain of whole-part relations. Either putting together parts of an object or separating an object into parts can be seen as creating or destroying companionship relationships.

Finally, the verb cut, which does not generally take an oblique object, does so in example (44b), where it is subsumed into the conative construction, thus suggesting an attempted action. This use is licensed by a metaphor with a noneffectual action in the source and an effectual action in the target, i.e. we understand the action of cutting the bread as if it was attempted but not necessarily carried into effect. This case is therefore the converse of the one for the adaptation of laugh to the caused-motion construction. What the metaphor does is ask us to understand one type of actor-object relationship in terms of another type. This cognitive operation is 
possible because the two kinds of action have a number of relevant features in common: they are goal-oriented (there is an intended effect on the object), there is motion and potential contact by impact, and the intended effect on the object is generic (i.e., not specific such as a change of state). Thus, change-of-state verbs such as bend, break, and smash cannot be mapped onto generic effectual actions (i.e., those that only code a very generic effect).

It could be argued that this meaning effect does not originate in a metaphorical mapping but rather results from constructional coercion as defined by Michaelis (2003). Constructional coercion is the meaning adaptation process whereby a construction imposes part of its meaning structure on a lexical configuration. In this view, the conative construction would require the adaptation of the meaning of cut from an effectual action with a visible impact on the object to an attempted action directed to an object. The LCM admits the existence of constructional coercion, but it further argues that coercion is not arbitrary but motivated. We need reliable criteria that allow us to determine and therefore predict when coercion is possible and when it is not. The possibility or impossibility of setting up metaphorical correlations between two verbal predicate types is one such criterion. There are other criteria - the internal constraints on lexical-constructional subsumption - that look at coercion as a matter of the internal configuration of lexical and constructional templates. We now turn to such constraints.

There are two broad groups of internal constraints on lexical-constructional subsumption. One group relates to the conditions for a lexical template to be regarded as internally compatible with or in need to be adapted to a constructional template. The other group deals with the instantiation conditions of constructional variables.

Let us first deal with the first kind of internal constraint. The simplest case is full matching. Here, a lexical item is required to respond to all constructional requirements without doing violence to its internal configuration. For example, the verb drink has a transitive use (e.g. John drank the beer). Following Van Valin's (2005) Aktionsart distinctions, drink is an activity predicate that can be converted into an active accomplishment by the addition of a resultative component. This is captured in a lexical template through a BECOME operator that ranges over the second argument or complement variable. The transitive construction similarly requires two argument variables, the second of which is affected by a BECOME operator: 


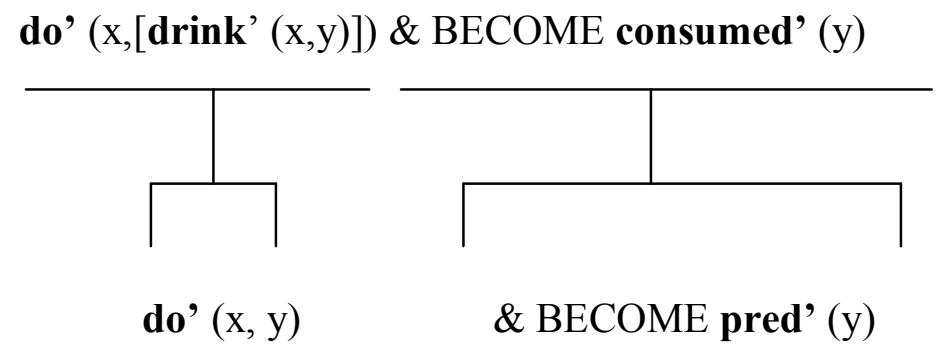

But drink can also appear in the intransitive form (e.g. We just want to drink and be merry). The intransitive form requires the elimination of the second argument variable. In a constructional framework there are two ways of explaining this phenomenon. One is to postulate that, since drink is not a naturally intransitive predicate like breathe, run, or walk, making it part of the intransitive construction requires some internal adaptation of drink, which thus loses its second argument variable in its formal expression. But note that the intransitive use of a transitive verb is different in meaning from the intransitive use of a naturally intransitive verb. Even though the second argument has been dropped from formal expression, it is still latent, which does not suggest a valence reduction phenomenon of the kind postulated by Dik (1997a). ${ }^{16}$ Another way of addressing this issue is to postulate a special form of transitive construction where the object has been omitted (the objectless transitive construction; cf. Lemmens 2006) or, as Goldberg (2001) puts it, de-emphasized or de-profiled (the deprofiled object construction) for discourse reasons while the action receives prominence. This formulation is in agreement with our previous discussion on level-1 cued inferencing: the hearer is cued by the deprofiled object construction to recover the missing argument inferentially from the context or from world knowledge. The intransitive construction, on the other hand, cannot cue such a process since it is by definition a true objectless construction. Furthermore, our account dispenses with the need to postulate verbal valency reduction processes in cases of intransitivization like the one for drink discussed above, or for other verbal predicates such as read (cf. He read the whole book; He read for hours before going to sleep), write (cf. She wrote a novel; She didn't write last night), or kill (cf. The sheriff killed the gunman; Stop me before I kill again) in

\footnotetext{
16 In a similar way, Van Valin and LaPolla (1997: 122-125) propose the existence of an inherent argument, specifying the nature of the process but not obligatorily present in the syntax.
} 
contexts in which there is some discourse reason for placing prominence on the verbal process (e.g. iteration, contrast, topicality). Since the object is recoverable, there is no real reduction process of the verbal arguments. This also means that we cannot postulate a subsumption process of these predicates into the intransitive construction, which would require full deletion of the object.

Another case of internal constraint is the event identification condition, which requires the various subevents (i.e. bundles of operators and variables) into which a lexical and a constructional configuration can be segmented to match. It can be illustrated by the adscription of the verb break to the inchoative construction (cf. Cortés 2007, this volume). This construction, which can be listed as an objectless construction where the object has been promoted to subject status, occurs with predicates expressing either a telic accomplishment or an achievement, but not with states, activities - or their corresponding causatives - and with active accomplishments. Thus, it can be applied to pure change of state verbs like break (cf. The child broke the window; The window broke) but not to verbs like see (cf. We all saw the picture; *The picture saw), which denotes a state, or to predicates like eat or drink (cf. The child drank her milk; *Her milk drank), which can be active accomplishments. These situations are represented in (46)-(49) below, where the asterisks represent lexical-constructional mismatches:

$\left[\right.$ Caus $_{1}$ Fact $\left._{1}\right]$

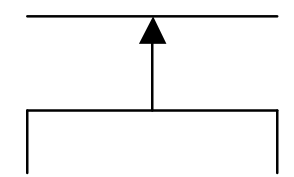

do' $(\mathrm{x}, \varnothing)$ CAUSE
[BECOME/ INGR pred' $(\mathrm{x})] 1=\mathrm{x}$

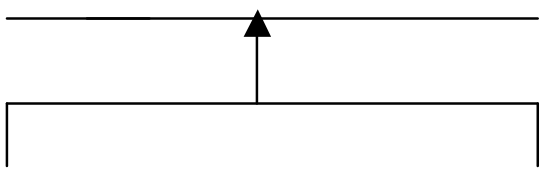

[BECOME broken $(\mathrm{y})]$
[Caus ${ }_{1}$ Fact $\left._{1}\right]$

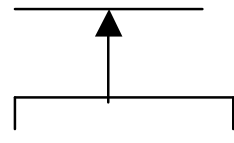

$* * *$
[BECOME/ INGR pred' (x)] $1=x$

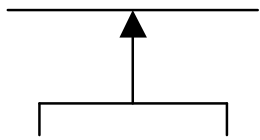

$* * *$

see' $(x, y)$ 
$\left[\mathrm{Caus}_{1}\right.$ Fact $\left._{1}\right] \quad[\mathrm{BECOME} / \mathrm{INGR}$ pred' $(\mathrm{x})] 1=\mathrm{x}$
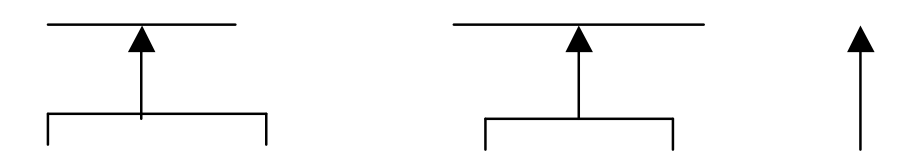

do' $(\mathrm{x}, \varnothing)$ CAUSE

*** $\quad[$ feel' $(\mathrm{y},[$ pred'] $)]$

(49)

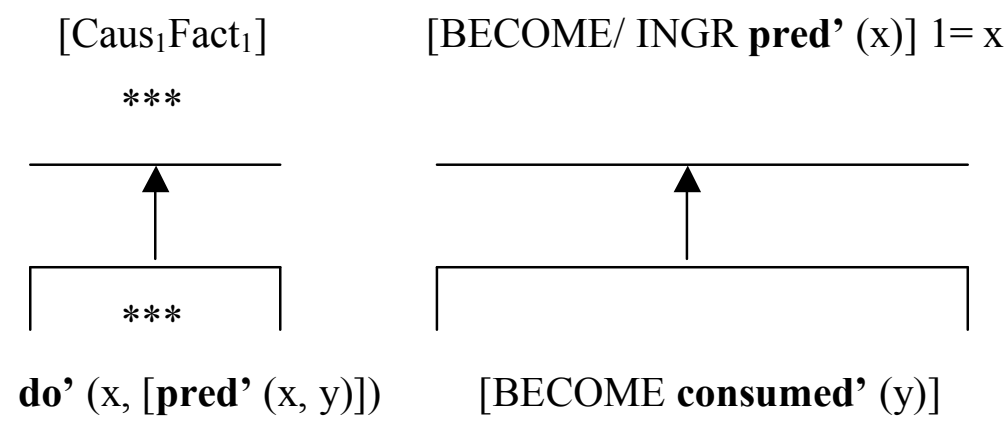

A third constraint is the lexical class constraint, which accounts for restrictions that class ascription places on lexical-constructional subsumption. Compare:

(50) a. Your son broke my videotape.

b. The CIA destroyed the videotape.

(51) a. My videotape broke.

b. *The videotape destroyed.

(52) a. do' (x, Ø) CAUSE [BECOME broken (y)]

b. do' $(\mathrm{x}, \varnothing)$ CAUSE [BECOME destroyed $(\mathrm{y})]$

We may wonder why if break and destroy have the same logical representation, as can be seen in (52), and the same transitive use, as evidenced in (51), only break can take part in the inchoative construction. The reason is that break and destroy belong to different lexical classes: the former is a change-of-state predicate, while the latter is an existential predicate indicating cessation of existence. The properties inherited 
from the lexical class can be built into the lexical template thus going beyond the basic logical form. The lexical template for the verb destroy should then include a specification of cessation of existence in the Aktionsart module based on semantic primes, further decomposing [BECOME destroyed (y)] into [BECOME NOT exist' (y)], while the idea of severe damage involved in destroyed should be transferred to the semantic module, which is based on amalgams of lexical functions (or operators) ranging over internal variables. We thus have the following refined representation of destroy, where Caus, Magn, and Dam are lexical functions that indicate causation, intensity, and physical damage respectively:

\section{(53) [CausMagnDam 12 do' $(x, \varnothing)$ CAUSE [BECOME NOT exist' (y)]}

$$
\mathrm{x}=1, \mathrm{y}=2
$$

The representation in (53) reads as follows: there is an action performed by an actor such that the action has caused great damage to an object, thus resulting in the object ceasing to exist as such. The mismatch between this description and the inchoative construction is evident from a consideration of (54) below, where the resultative part of the logical structure of the lexical template is different from its expected counterpart in the constructional template. In the lexical template pred' is nonexistence, while in the constructional template pred' is any state different from the initial state.

$\left[\mathrm{Caus}_{1}\right.$ Fact $\left._{1}\right] \quad[\mathrm{BECOME} / \mathrm{INGR}$ pred' $(\mathrm{x})] 1=\mathrm{x}$

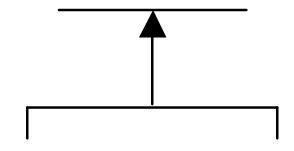

do' $(\mathrm{x}, \varnothing)$ CAUSE

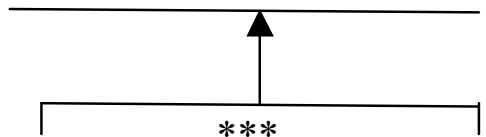

[BECOME NOT exist' (y)]

A fourth internal constraint is lexical blocking. Here, one of the components of the lexical template can block the fusion with a certain construction given that this component is a suppletive form. Accordingly, kill does not occur in the inchoative construction since its corresponding objectless form is suppletive, i.e. die, as in $\mathrm{He}$ 
killed the goose/ The goose died. Since the linguistic system has already coded the form die in the lexicon with the same meaning, then the expected inchoative form of kill is blocked. In Spanish we have a comparable situation with only one difference. Spanish codes three values: matar ('kill'), morir ('die'), matarse ('kill oneself'). Note that an expression like El niño se mató ('The child killed himself [accidentally]') usually suggests that the child accidentally did something and as a result he died but there is no external agent as a possible cause of his death as in El asesino mató al niño ('The murderer killed the child') or La enfermedad mató al niño ('The disease killed the child').

Now we turn our attention briefly to the second broad group of constraints, i.e. those pertaining to the limitations on the way constructional variables are realized as subsumption takes place. One such constraint is what we call predicate-argument conditioning. Sometimes the co-instantiation of the verbal predicate and one of its arguments can place restrictions on the kind of instantiating element that we can have for other constructional arguments. Thus, in the caused-motion construction we have a basic constructional structure of the type $\mathrm{X}$-pred-Y $(=\mathrm{NP})-\mathrm{Z}(=\mathrm{PP})$. In principle, the constructional template can take any verb participant role to instantiate the $\mathrm{Y}$ element, which can be either human or non-human, as illustrated by the following Spanish variant of the caused-motion construction: Quiero a este niño lejos de aquí ('I want this child far from here'); Quiero esta silla en otra parte ('I want this chair somewhere else'). However, once the predicate and PP slots have been filled in, this choice constrains the kind of Y element that we can have. Me metió en una profunda depresión ('He drove me into a deep depression'), the $\mathrm{Y}$ element (me) has been realized by a human verb role; we cannot have a non-human element (cf. *Metió a la silla en una profunda depresión 'He drove the chair into a deep depression').

A second constraint within this group, internal variable conditioning, occurs when the internal predicate variables place constraints on the nature of both the predicate and constructional arguments. A clear example is supplied by the use of the Spanish verb volver in caused-resultative configurations: Me vas a volver loco ('You're driving me crazy'). There is a tendency for the resultative predicate to be axiologically negative: \#Me vas a volver amable ('You're driving me kind').

To end our discussion of subsumption, we must also consider the way it works outside core grammar. In general, levels 2, 3, and 4 subsumption processes are a matter of semantic compatibility between the idiomatic parts of the construction and 
the conceptual material that is intended to realize its variable parts. We refer to this phenomenon as morphosyntactic parametrization. This constraint spells out the actual morphosyntactic type of the constructional unit in question. For example, as argued above the Can You Y? construction blocks out certain lexical classes (e.g. states and non-active accomplishments) as possible candidates for the Y element. In a similar way, the $\mathrm{X}$ and the $\mathrm{Y}$ elements in the 'What's $\mathrm{X}$ Doing Y?' construction are constrained such that the $\mathrm{X}$ is usually a NP, while the Y element is a PP. The same can be said of the Double Be construction (McConvell 1988; Tuggy 1996; Massam 1999), which is used to draw attention to a given situation while asserting its truthfulness, as in The thing is, is that he didn't tell the truth. In this construction, which takes the form ' $\mathrm{X}$ is, is $\mathrm{Y}$ ', the $\mathrm{X}$ and $\mathrm{Y}$ elements are clearly defined by a number of features: $\mathrm{X}$, which is the topic, is marked by a high tone, whereas $\mathrm{Y}$, which is the focus, takes a low tone; $\mathrm{Y}$ can be freely realized by any that-clause but $\mathrm{X}$ is limited to a few options: the thing, the problem, the question, what I mean, and what happens.

\section{Conclusion}

The present paper has proposed the Lexical Constructional Model as an explanatorily adequate model for the investigation of the way in which lexical and constructional representations interact. The LCM is intended to be operational at all levels of linguistic description, including pragmatics and discourse. Thus, it has a level 1 or core module consisting of elements of syntactically relevant semantic interpretation, a pragmatic or level 2 module that accounts for low-level inferential aspects of linguistic communication, a level 3 module dealing with high-level inferences (i.e. illocutionary force), and finally a level 4 module that accounts for the discourse aspects of the LCM, especially cohesion and coherence phenomena. Each level is either subsumed into a higher-level constructional configuration or acts as a cue for the activation of a relevant conceptual structure that yields an implicit meaning derivation. At the heart of the LCM we find the notions of lexical and constructional template, which are the building blocks of the model. The principled interaction between lexical and constructional templates supplies the central or core meaning layer for other more peripheral operations - involving implicated meaning - to take 
place. Meaning construction in the LCM revolves around two key processes, cueing and subsumption. Subsumption is a key meaning production mechanism that consists in the principled incorporation of lexical and/or constructional templates from one representational level into higher-level constructional representations. At the level of core grammar constructional templates "coerce" lexical templates. We distinguish two kinds of constraints on coercion: internal and external. The former arise from the semantic properties of the lexical and constructional templates and do not affect the Aktionsart ascription of the predicates involved. The latter do involve Aktionsart changes and result from the possibility or impossibility of performing high-level metaphoric and metonymic operations on the lexical items involved in the subsumption process. Internal constrains specify the conditions under which a lexical template may modify its internal configuration. Finally, cueing or cued inferencing is a form of constraining non-explicit meaning on the basis of lexical and constructional clues. It takes place at all levels of meaning derivation as an alternative to subsumption. Thus, at the level of core grammar, it accounts for inferences obtained by making contextual adjustments to the meaning of some predicates. At other levels it accounts for meaning implications based on potential conceptual connections between propositions (the case of discourse), or on metonymic activations or highlevel (for illocution), and low-level (for implicature) situational models or scenarios.

\section{References}

Alonso Ramos, Margarita. 2002. "Colocaciones y contorno en la definición lexicográfica.” Lingüística Española Actual 24(1): 63-96.

Bach, Kent. 1994. “Conversational impliciture”. Mind and Language 9(2): 124-162.

Baker, Collin F., and Josef Ruppenhofer. 2003. “FrameNet's Frames vs. Levin's Verb Classes". Proceedings of the $28^{\text {th }}$ annual meeting of the Berkeley Linguistics Society, ed. by Julie Larson and Mary Paster, 27-38. Berkeley, CA: University of California Linguistics Department.

Beaugrande, Robert de. 1980. Text, discourse and process. Norwood, NJ: Ablex.

Bender, Emily and Andreas Kathol. 2001. "Constructional effects of Just Because ... Doesn't Mean..." Proceedings of the 27th annual meeting of the Berkeley Linguistics Society. Berkeley, Cal. 
Bergen, Benjamin K. and Nancy Chang. 2005. "Embodied construction grammar in simulation-based language understanding." Construction grammars: Cognitive grounding and theoretical extensions, ed. by Jan-Ola Östman and Mirjam Fried, 147-190. Amsterdam: John Benjamins.

Boas, Hans C. 2003. A constructional approach to resultatives. Stanford, CA: CSLI Publications.

Boas, Hans C. 2006. "A Frame-Semantic Approach to Identifying Syntactically Relevant Elements of Meaning." Contrastive studies and valency, ed. by Petra Steiner, Hans C. Boas, and Stefan Schierholz, 119-149. Frankfurt: Peter Lang.

Boas, Hans C. 2008. "Resolving Form-Meaning Discrepancies in Construction Grammar." Constructional reorganization, ed. by Jaakko Leino. Amsterdam: John Benjamins.

Butler, Christopher S. 2003. Structure and function. A guide to three major structuralfunctional theories. 2 vols. Amsterdam: John Benjamins.

Butler, Christopher S. and Francisco Gonzálvez-García 2005. "Situating FDG in functional-cognitive space: An initial study." Studies in Functional Discourse Grammar, ed. by J. Lachlan Mackenzie and M.A. Gómez-González, 109-158. Berlin: Peter Lang.

Carston, Robyn. 2002. Thoughts and utterances: The pragmatics of explicit communication. Oxford: Basil Blackwell.

Carston, Robyn. 2004. "Explicature and semantics." Semantics: A reader, ed. by Stephen Davis and Brendan S. Gillon, 817-845. Oxford: Oxford University Press.

Cortés, Francisco. 2007. The English constructicon. Unpublished manuscript. University of La Laguna.

Croft, William. 1991. Syntactic categories and grammatical relations. Chicago: The University of Chicago Press.

Croft, William. 2001. Radical Construction Grammar. Oxford: Oxford University Press.

Culicover, Peter W. and Ray Jackendoff. 2005. Simpler Syntax. Oxford: Oxford University Press.

Dik, Simon C. 1997a. The Theory of Functional Grammar. Part 1: The structure of the clause. Edited by Kees Hengeveld. Berlin: Mouton de Gruyter. 
Dik, Simon C. 1997b. The Theory of Functional Grammar. Part 2: Complex and derived constructions. Edited by Kees Hengeveld. Berlin: Mouton de Gruyter.

Dowty, David. 1979. Word meaning and Montague Grammar. Dordrecht: Foris.

Faber, Pamela and Ricardo Mairal. 1999. Constructing a lexicon of English verbs. Berlin: Mouton de Gruyter.

Fawcett, Robin. 1980. Cognitive linguistics and social interaction: Towards an integrated model of a Systemic Functional Grammar and the other components of an interacting mind. Heidelberg: Julius Groos.

Fillmore, Charles. 1985. "Frames and the semantics of understanding." Quaderni di Semantica 6(2): 222-254.

Fillmore, Charles J. and Beryl T. S. Atkins. 1992. "Towards a frame-based organization of the lexicon: The semantics of RISK and its neighbors." Frames, fields, and contrast: New essays in semantics and lexical organization, ed. by Adrienne Lehrer and Eva F. Kittay, 75-102 Hillsdale: Lawrence Erlbaum Associates.

Fillmore, Charles J. and Beryl T. S. Atkins. 1994. "Starting where the dictionaries stop: The challenge for computational lexicography." Computational approaches to the lexicon, ed. by Beryl T. S. Atkins and Antonio Zampolli, 349-393. Oxford: Oxford University Press.

Fillmore, Charles J., Paul Kay and Mary Catherine O'Connor. 1988. "Regularity and idiomaticity in grammatical constructions: The case of let alone." Language 64: 501-538.

Goldberg, Adele. 1995. A Construction Grammar approach to argument structure, Chicago: University of Chicago Press.

Goldberg, Adele. 2001. "Patient Arguments of causative verbs can be omitted: the role of information structure in argument distribution." Language Sciences 34: $503-524$.

Goldberg, Adele. 2006. Constructions at work: The nature of generalization in language. Oxford: Oxford University Press.

Goldberg, Adele, Devin M. Casenhiser and Nitya Sethuraman, 2005. "The role of prediction in construction-learning." Journal of Child Language 32(2): 407426. 
Gonzálvez-García, Francisco. 2008. "Constructional polysemy meets coercion: The case of the subjective-transitive construction in English and Spanish." forthcoming.

Gonzálvez-García, Francisco and Christopher S. Butler. 2006. "Mapping functionalcognitive space." Annual Review of Cognitive Linguistics 5: 39-96.

Halliday, Michael A. K. 1994. An introduction to Functional Grammar. 2nd. edition. London: Edward Arnold.

Halliday, Michael A. K. and Christian M. I. M. Matthiessen. 2004. An introduction to functional grammar, 3rd edition. London: Hodder Arnold.

Hengeveld, Kees. 2004. "The architecture of a Functional Discourse Grammar." $A$ new architecture for Functional Grammar, ed. by Lachlan Mackenzie and María Ángeles Gómez-González, 1-21. Berlin: Mouton de Gruyter.

Hengeveld, Kees and J. Lachlan Mackenzie. 2006. "Functional Discourse Grammar." Encyclopaedia of language and linguistics, vol. 4. 2nd edition, ed. by Keith Brown, 668-676. Oxford: Elsevier.

Hengeveld, Kees, and J. Lachlan Mackenzie. 2008. Functional Discourse Grammar. A typologically-based theory of language structure, forthcoming. Oxford: Oxford University Press.

Hoey, Michael. 1983. On the surface of discourse. London: George Allen and Unwin. Holmes, Jasper and Richard Hudson. 2000. “Just Because X Doesn't Mean Y”. Paper delivered at the Linguistics Association of Great Britain, Spring Meeting. University College London.

Jackendoff, Ray. 1997. The architecture of the language faculty. Cambridge, MA.: The MIT Press.

Jackendoff, Ray. 2002. Foundations of language. Oxford: Oxford University Press.

Jackendoff, Ray. 2007. Language, consciousness, culture: Essays on mental structure (Jean Nicod Lectures). Cambridge, Mass.: MIT Press

Kay, Paul and Charles J. Fillmore. 1999. "Grammatical constructions and linguistic generalizations: The 'What's X doing Y' construction." Language 75: 1-33.

Lakoff, George. 1987. Women, fire and dangerous things: What categories reveal about the mind. Chicago: University of Chicago Press.

Lakoff, George and Mark Johnson. 1980. Metaphors we live by. Chicago: The University of Chicago Press. 
Lakoff, George and Mark Johnson. 1999. Philosophy in the flesh. New York: Basic Books.

Langacker, Ronald W. 1987. Foundations of Cognitive Grammar: Volume 1: Theoretical prerequisites. Stanford, CA: Stanford University Press.

Langacker, Ronald W. 1991. Foundations of Cognitive Grammar. Vol. 2: Descriptive application. Stanford, CA: Stanford University Press.

Langacker, Ronald W. 1999. Grammar and conceptualization. Berlin: Mouton de Gruyter.

Langacker, Ronald W. 2001. "Discourse in Cognitive Grammar." Cognitive Linguistics 12(2): 143-188.

Langacker, Ronald W. 2005. "Construction Grammars: cognitive, radical, and less so." Cognitive Linguistics. Internal dynamics and interdisciplinary interaction, ed. by Francisco J. Ruiz de Mendoza Ibáñez and Sandra Peña Cervel, 101-159. Berlin: Mouton de Gruyter.

Langacker, Ronald W. 2008. Cognitive Grammar: A basic introduction. Oxford: Oxford University Press.

Lemmens, Maarten. 2006. "More on objectless transitives and ergativization patterns in English." Constructions SV1-6/2006. (www.constructions-online.de)

Levin, Beth. 1993. English verb classes and alternations. A preliminary investigation. Chicago: The University of Chicago Press.

Levin, Beth and M. Rappaport Hovav. 2005. Argument realization. Cambridge: Cambridge University Press. [Research Surveys in Linguistics Series.]

Longacre, Robert E. 1972. Hierarchy and universality of discourse constituents in New Guinea languages: Discussion. Washington, D.C.: Georgetown University Press.

Mairal Usón, Ricardo and Pamela Faber. 2002. "Functional Grammar and lexical templates". New perspectives on argument structure in Functional Grammar, ed. by Ricardo Mairal Usón and María J. Pérez Quintero, 41-98. Berlin: Mouton de Gruyter.

Mairal, Ricardo and Pamela Faber. 2007. "Lexical templates within a functional cognitive theory of meaning." Annual Review of Cognitive Linguistics 5: 137172.

Mairal Usón, Ricardo and Francisco José Ruiz de Mendoza Ibáñez. 2008. "Internal and external constraints in meaning construction: the lexicon-grammar 
continuum." Estudios de Filología Inglesa: Homenaje a la Dra. Asunción Alba Pelayo. Madrid: UNED.

Martin, James R. 1992. English text: System and structure. Amsterdam: John Benjamins.

Massam, Diane. 1999. "Thing Is constructions: The thing is, is what's the right analysis?" English Language and Linguistics 3: 335-352.

McConvell, Patrick. 1988. "To be or double be: current change in the English copula." Australian Journal of Linguistics 8: 287-305.

Mel'čuk, Igor. 1989. "Semantic primitives from the viewpoint of the Meaning-Text Linguistic Theory." Quaderni di Semantica 10(1): 65-102.

Mel'čuk, Igor, André Clas and Alain Polguère. 1995. Introduction à la Lexicologie Explicative et Combinatoire. Louvain-la-Neuve: Duculot.

Mel'čuk, Igor and Leo Wanner. 1996. "Lexical functions and lexical inheritance for Emotion lexemes in German." Recent trends in Meaning-Text Theory, ed. by Leo Wanner, 209-227. Amsterdam: John Benjamins.

Michaelis, Laura. 2003. "Word meaning, sentence meaning, and syntactic meaning." Cognitive approaches to lexical semantics, ed. by Hubert Cuyckens, René Dirven and John R. Taylor, 93-122. Berlin: Mouton de Gruyter.

Nichols, Johanna. 1984. Functional theories of grammar. Annual Review of Anthropology 13: 97-117

Nuyts, Jan. 2005. "Brothers in arms? On the relations between Cognitive and Functional Linguistics." Cognitive Linguistics. Internal dynamics and interdisciplinary interaction, ed. by Francisco José Ruiz de Mendoza Ibáñez, and Sandra Peña Cervel, 69-100. Berlin: Mouton de Gruyter.

Otal Campo, José Luis and Francisco José Ruiz de Mendoza Ibáñez. 2007. “Modeling thought in language use: at the crossroads between discourse, pragmatics, and cognition." Jezikoslovlje 8(2): 115-167.

Panther, Klaus-Uwe. 2005. "The role of conceptual metonymy in meaning construction." Cognitive Linguistics. Internal dynamics and interdisciplinary interaction, ed. by Francisco José Ruiz de Mendoza Ibañez and M. Sandra Peña Cervel, 353-386. Berlin: Mouton de Gruyter.

Panther, Klaus-Uwe, and Linda Thornburg. 1998. "A cognitive approach to inferencing in conversation." Journal of Pragmatics 30: 755-769. 
Panther, Klaus-Uwe, and Linda Thornburg. 2003. "Metonymies as natural inference and activation schemas: the case of dependent clauses as independent speech acts." Metonymy and pragmatic inferencing, ed. by Klaus-Uwe Panther and Linda Thornburg, 127-147. Amsterdam: John Benjamins.

Pérez, Lorena and Francisco Ruiz de Mendoza. 2002. "Grounding, semantic motivation, and conceptual interaction in Indirect Directive Speech Acts." Journal of Pragmatics 34(3): 259-284.

Perry, John. 1977. "Frege on demonstratives.” Phylosophical Review 86: 474-497.

Pustejovsky, James. 1995. The Generative Lexicon. Cambridge, Mass.: MIT Press.

Récanati, François. 1989. "The pragmatics of what is said". Mind and Language 4: 294-328.

Ruiz de Mendoza Ibáñez, Francisco José. 2007. "High level cognitive models: in search of a unified framework for inferential and grammatical behavior." Perspectives on metonymy, ed. by Krzysztof Kosecki, 11-30. Frankfurt, Main. Peter Lang.

Ruiz de Mendoza Ibáñez, Francisco José and Annalisa Baicchi. 2007. "Illocutionary constructions: cognitive motivation and linguistic realization." Explorations in pragmatics: Linguistic, cognitive, and intercultural aspects, ed. by Istvan Kecskes and Laurence Horn, 95-128. Berlin: Mouton de Gruyter.

Ruiz de Mendoza Ibáñez, Francisco José and Ricardo Mairal Usón. 2007a. "Levels of semantic representation: where lexicon and grammar meet." Interlingüistica 17.

Ruiz de Mendoza Ibáñez, Francisco José and Ricardo Mairal Usón. 2007b. “Highlevel metaphor and metonymy in meaning construction." Aspects of meaning construction, ed. by Günter Radden, Klaus-Michael Köpcke, Thomas Berg, and Peter Siemund, 33-49. Amsterdam: John Benjamins..

Ruiz de Mendoza Ibáñez, Francisco José and Ricardo Mairal Usón. 2008a. "Levels of description and constraining factors in meaning construction: an introduction to the Lexical Constructional Model." Folia Linguistica vol. 42: forthcoming.

Ruiz de Mendoza, Francisco José and Ricardo Mairal Usón. 2008b. "Challenging systems of lexical representation." Journal of English Studies 4: forthcoming.

Ruiz de Mendoza Ibáñez, Francisco José and José Luis Otal Campo. 1997. "Communication strategies and realization procedures." ATLANTIS. Revista 
de la Asociación Española de Estudios Anglonorteamericanos 19(1): 297314.

Ruiz de Mendoza Ibáñez, Francisco José and Lorena Pérez Hernández. 2003. "Cognitive operations and pragmatic implication." Metonymy and pragmatics, ed. by Klaus-Uwe Panther and Linda Thornburg, 23-49. Berlin: Mouton de Gruyter.

Sadock, Jerrold M. and Arnold M. Zwicky. 1985. "Speech act distinctions in syntax." Language typology and syntactic description, ed. by Timothy Shopen, 155-196. Cambridge: Cambridge University Press.

Schank, Roger C. and Robert P. Abelson. 1977. Scripts, plans, goals and understanding: an inquiry into human knowledge structures. Hillsdale, NJ: Lawrence Erlbaum.

Sperber, Dan, Wilson, Deirdre. 1995. Relevance. Communication and cognition. Oxford: Basil Blackwell. $2^{\text {nd }}$ ed.

Steen, Gerard. 2005. "Basic Discourse Acts: towards a psychological theory of discourse segmentation." In Cognitive Linguistics. Internal dynamics and interdisciplinary interaction, ed. by Francisco José Ruiz de Mendoza Ibáñez and Sandra Peña Cervel, 283-312. Berlin: Mouton de Gruyter.

Stefanowitsch, Anatol. 2003. "A construction-based approach to indirect speech acts." Metonymy and pragmatic inferencing, ed. by Klaus-Uwe Panther and Linda L. Thornburg, 105-126. Amsterdam: John Benjamins.

Thornburg, Linda and Klaus-Uwe Panther. 1997. "Speech act metonymies." Discourse and perspective in Cognitive Linguistics, ed. by Wolf-Andreas Liebert, Gisela Redeker and Linda R. Waugh, 205-219. Amsterdam: John Benjamins.

Tuggy, David. 1996. "The thing is is that people talk that way. The question is is why?" Cognitive Linguistics in the redwoods: The expansion of a new paradigm in linguistics, ed. by Eugene H. Casad, 713-752. Berlin: Mouton de Gruyter.

Van Valin, Robert D. Jr. 2005. The syntax-semantics interface: An introduction to Role and Reference Grammar, Cambridge: Cambridge University Press.

Van Valin, Robert D. Jr. 2008. "Lexical representation, co-composition, and linking syntax and semantics." New developments in the Generative Lexicon, ed. by James Pustejovsky et al., forthcoming. Dordrecht: Kluwer. 
Van Valin, Robert D. Jr. and Randy LaPolla. 1997. Syntax: structure, meaning and function. Cambridge: Cambridge University Press.

Van Valin, Robert D. Jr. and David P. Wilkins 1993. "Predicting syntactic structure from semantic representations: remember in English and its equivalents in Mparntwe Arrernte." Advances in Role and Reference Grammar, ed. by Robert D. Van Valin Jr., 499-534. Amsterdam: John Benjamins.

Vendler, Zeno. 1967. Linguistics in philosophy. Ithaca, NY: Cornell University Press.

Weilbacher, Hunter and Hans C. Boas. 2006. “Just Because' two constructions look alike in two languages doesn't mean that they share the same properties: Towards contrastive Construction Grammars." $4^{\text {th }}$ International Construction Grammar Conference, unpublished paper. Tokyo, Japan.

Winter, Eugene O. 1982. Towards a contextual grammar of English. London: George Allen and Unwin. 


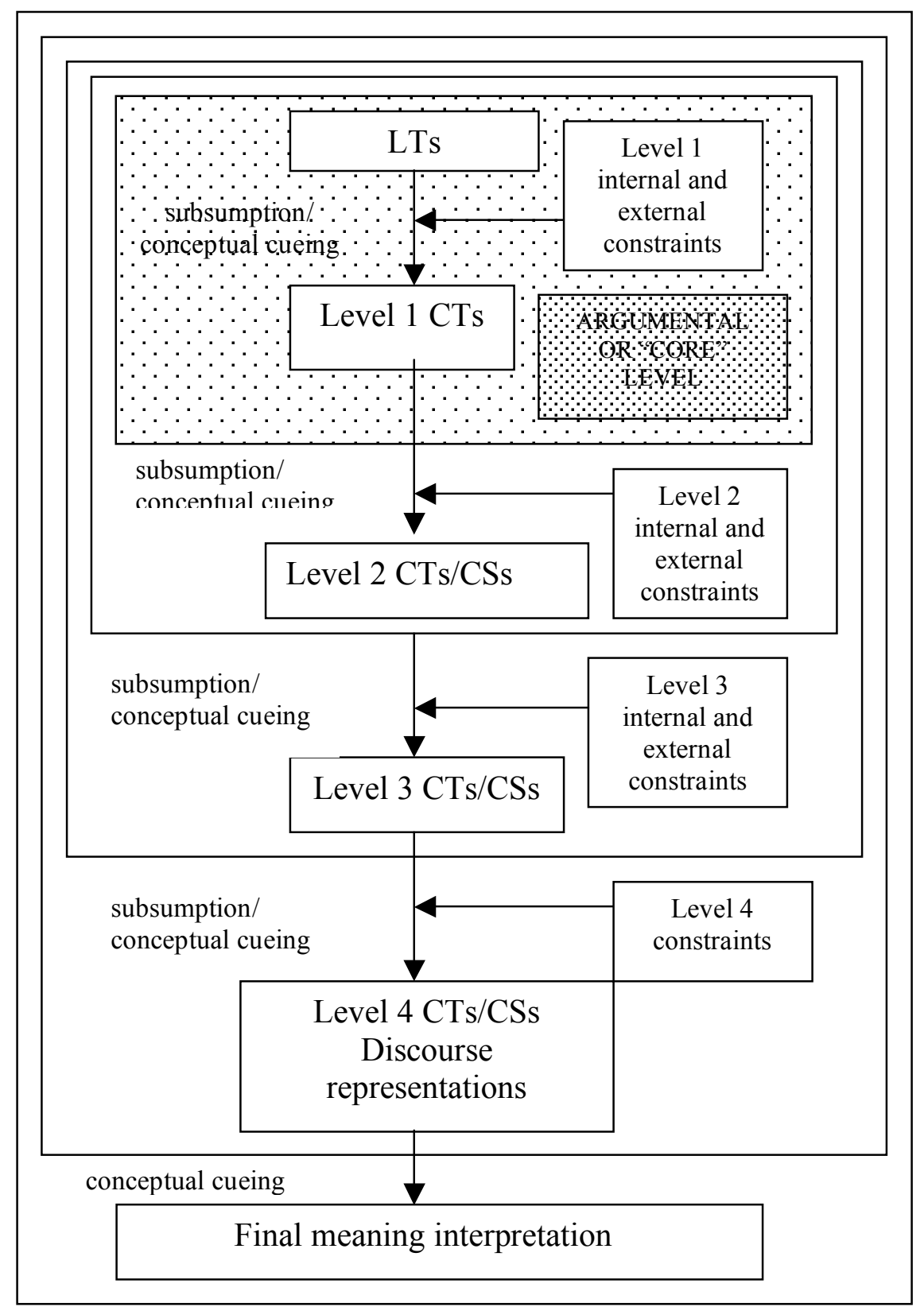

Figure 1: The overall architecture of the Lexical Constructional Model $\mathrm{LT}=$ lexical template; $\mathrm{CT}=$ constructional template; $\mathrm{CS}=$ Conceptual Structure 


\begin{tabular}{|c|c|c|c|}
\hline Verb Class & LOGICAL STRUCTURE & EXAMPLE & INSTANTIATION OF LS \\
\hline State & predicate' $(\mathrm{x})$ or $(\mathrm{x}, \mathrm{y})$ & see & see' $(x, y)$ \\
\hline Activity & do' $(\mathrm{x}$, [predicate' $(\mathrm{x})$ or $(\mathrm{x}, \mathrm{y})]$ & run & do' $(x,[$ run' $(x)])$ \\
\hline Achievement & $\begin{array}{l}\text { INGR predicate' }(\mathrm{x}) \text { or }(\mathrm{x}, \mathrm{y}), \text { or } \\
\text { INGR do' }(\mathrm{x}, \text { [predicate' }(\mathrm{x}) \text { or }(\mathrm{x}, \mathrm{y})]\end{array}$ & $\begin{array}{l}\text { pop (burst into } \\
\text { tears) }\end{array}$ & INGR popped' (x) \\
\hline Semelfactive & SEML predicate' $(\mathrm{x})$ or $(\mathrm{x}, \mathrm{y})$ & glimpse, cough & SEML see' $(x, y)$ \\
\hline & SEML do' $(x$, [predicate' $(x)$ or $(x, y)$ ] & & \\
\hline Accomplishment & $\begin{array}{l}\text { BECOME predicate' }(\mathrm{x}) \text { or }(\mathrm{x}, \mathrm{y}), \text { or } \\
\text { BECOME do' (x, [predicate' }(\mathrm{x}) \text { or } \\
(\mathrm{x}, \mathrm{y})]\end{array}$ & receive & BECOME have' $(x, y)$ \\
\hline $\begin{array}{l}\text { Active } \\
\text { accomplishment }\end{array}$ & $\begin{array}{l}\text { do' }^{\prime}\left(\mathrm{x}, \quad \text { predicate }_{\mathbf{1}},(\mathrm{x}, \quad(\mathrm{y}))\right] \quad \& \\
\text { BECOME predicate }_{\mathbf{2}}(\mathrm{z}, \mathrm{x}) \text { or }(\mathrm{y})\end{array}$ & drink & $\begin{array}{l}\text { do' }(x,[\text { drink' }(x, y)]) \& \\
\text { BECOME consumed' }(y)\end{array}$ \\
\hline $\begin{array}{l}\text { Causative } \\
\text { accomplishment }\end{array}$ & $\begin{array}{l}\alpha \text { CAUSES } \beta \text { where } \alpha, \beta \text { are LS of any } \\
\text { type }\end{array}$ & kill & $\begin{array}{l}{\left[\begin{array}{lll}\mathbf{d o}^{\prime} & (\mathrm{x}, & \varnothing\end{array}\right] \text { CAUSE }} \\
{\left[\begin{array}{l}\text { BECOME }[\mathbf{d e a d} '(\mathrm{y})]\end{array}\right.}\end{array}$ \\
\hline
\end{tabular}

Table 1: Verb classes in RRG

\begin{tabular}{|c|c|c|c|}
\hline & $\begin{array}{l}\text { Primary speech } \\
\text { functions }\end{array}$ & $\begin{array}{l}\text { Expected } \\
\text { response }\end{array}$ & $\begin{array}{l}\text { Discretionary } \\
\text { response }\end{array}$ \\
\hline Giving information & $\begin{array}{l}\text { Stating } \\
\text { John will come }\end{array}$ & $\begin{array}{l}\text { Acknowledging } \\
\text { Will he? }\end{array}$ & $\begin{array}{l}\text { Contradicting } \\
\text { No, he won't }\end{array}$ \\
\hline Giving goods-\&-services & $\begin{array}{l}\text { Offering } \\
\text { Shall I carry your bag? }\end{array}$ & $\begin{array}{l}\text { Accepting } \\
\text { Yes, please, do! }\end{array}$ & $\begin{array}{l}\text { Rejecting } \\
\text { No, thanks }\end{array}$ \\
\hline Demanding information & $\begin{array}{l}\text { Questioning } \\
\text { What did John buy? }\end{array}$ & $\begin{array}{l}\text { Answering } \\
\text { A new car }\end{array}$ & $\begin{array}{l}\text { Disclaiming } \\
\text { I couldn't tell }\end{array}$ \\
\hline $\begin{array}{l}\text { Demanding } \\
\text { services }\end{array}$ & $\begin{array}{l}\text { Commanding } \\
\text { Wash the dishes! }\end{array}$ & $\begin{array}{l}\text { Undertaking } \\
\text { Sure! }\end{array}$ & $\begin{array}{l}\text { Refusing } \\
\text { I won't }\end{array}$ \\
\hline
\end{tabular}

Table 2: Primary speech functions and their associated responses 


\begin{tabular}{|c|c|c|c|}
\hline \multirow{2}{*}{$\begin{array}{c}\text { General } \\
\text { semantic } \\
\text { relation }\end{array}$} & \multirow{2}{*}{$\begin{array}{l}\text { Specific } \\
\text { semantic } \\
\text { relation }\end{array}$} & \multicolumn{2}{|c|}{ Examples } \\
\hline & & Implicit & Explicit \\
\hline \multirow[t]{4}{*}{ Elaboration } & Restatement & $\begin{array}{l}\text { She has the right work } \\
\text { experience and skills. } \\
\text { She can do the job. }\end{array}$ & $\begin{array}{l}\text { She has the right work } \\
\text { experience and skills; in } \\
\text { other words, she can do } \\
\text { the job. }\end{array}$ \\
\hline & Comment & $\begin{array}{l}\text { He spoke calmly; she } \\
\text { was surprised. }\end{array}$ & $\begin{array}{l}\text { He spoke calmly, which } \\
\text { surprised her. }\end{array}$ \\
\hline & Specification & $\begin{array}{l}\text { We all knew something: } \\
\text { the car had been stolen. }\end{array}$ & $\begin{array}{l}\text { We all knew that the car } \\
\text { had been stolen. }\end{array}$ \\
\hline & Exemplification & $\begin{array}{l}\text { Big companies are } \\
\text { growing bigger; witness } \\
\text { the number of mergers. }\end{array}$ & $\begin{array}{l}\text { Big companies are } \\
\text { growing bigger, as is } \\
\text { evidenced by the } \\
\text { number of mergers. }\end{array}$ \\
\hline \multirow[t]{3}{*}{ Extension } & Addition & $\begin{array}{l}\text { The bride wore a hand- } \\
\text { knitted gown; she also } \\
\text { carried a woolen } \\
\text { bouquet. }\end{array}$ & $\begin{array}{l}\text { The bride wore a hand- } \\
\text { knitted gown and } \\
\text { carried a woolen } \\
\text { bouquet. }\end{array}$ \\
\hline & Exception & $\begin{array}{l}\text { Chuck Norris does not } \\
\text { believe there should be } \\
\text { any action heroes; he is } \\
\text { the only exception. }\end{array}$ & $\begin{array}{l}\text { Chuck Norris does not } \\
\text { believe there should be } \\
\text { any action heroes } \\
\text { except for himself. }\end{array}$ \\
\hline & Alternation & $\begin{array}{l}\text { Perhaps she didn't know } \\
\text { how to reach out; } \\
\text { perhaps she didn't } \\
\text { really love me. }\end{array}$ & $\begin{array}{l}\text { Either she didn't know } \\
\text { how to reach out or she } \\
\text { didn't really love me. }\end{array}$ \\
\hline \multirow[t]{4}{*}{ Enhancement } & Time & $\begin{array}{l}\text { He had surgery; then he } \\
\text { checked himself out of } \\
\text { the hospital. }\end{array}$ & $\begin{array}{l}\text { After he had surgery, he } \\
\text { checked himself out of } \\
\text { the hospital. }\end{array}$ \\
\hline & Location & $\begin{array}{l}\text { We found the mummy; it } \\
\text { was inside a huge } \\
\text { chamber. }\end{array}$ & $\begin{array}{l}\text { We found the mummy } \\
\text { just where the old } \\
\text { manuscript said it was } \\
\text { located. }\end{array}$ \\
\hline & Cause & $\begin{array}{l}\text { They were pleased; the } \\
\text { engine worked well. }\end{array}$ & $\begin{array}{l}\text { They were pleased } \\
\text { because the engine } \\
\text { worked well. }\end{array}$ \\
\hline & Condition & $\begin{array}{l}\text { You can have the day off } \\
\text { tomorrow. But you have } \\
\text { to agree to work on } \\
\text { Saturday. }\end{array}$ & $\begin{array}{l}\text { You can have the day off } \\
\text { tomorrow on condition } \\
\text { that you agree to work } \\
\text { on Saturday. }\end{array}$ \\
\hline
\end{tabular}

Table 3: Some discourse relations 